\title{
Why Doesn't the United States Have a European- Style Welfare State?
}

\section{Citation}

Alesina, Alberto, Edward L. (Edward Ludwig) Glaeser, and Burce Sacerdote. 2001. “Why Doesn't the United States Have a European-Style Welfare State?" Brookings Papers on Economic Activity 2001 (2): 187-277.

\section{Published Version}

doi:10.1353/eca.2001.0014

\section{Permanent link}

http://nrs.harvard.edu/urn-3:HUL.InstRepos:12502088

\section{Terms of Use}

This article was downloaded from Harvard University's DASH repository, and is made available under the terms and conditions applicable to Other Posted Material, as set forth at http:// nrs.harvard.edu/urn-3:HUL.InstRepos:dash.current.terms-of-use\#LAA

\section{Share Your Story}

The Harvard community has made this article openly available.

Please share how this access benefits you. Submit a story.

\section{Accessibility}


ALBERTO ALESINA

Harvard University

EDWARD GLAESER

Harvard University

BRUCE SACERDOTE

Dartmouth College

\section{Why Doesn't the United States Have a European-Style Welfare State?}

EUROPEAN GOVERNMENTS REDISTRIBUTE income among their citizens on a much larger scale than does the U.S. government. European social programs are more generous and reach a larger share of citizens. European tax systems are more progressive. European regulations designed to protect the poor are more intrusive. In this paper we try to understand why.

The literature on the size of government is rich and varied. However, here we do not focus on the size of government as such, but rather on the redistributive side of government policies. Thus our goal is in one sense narrower than answering the question, "What explains the size of government?" since we focus on a single, but increasingly important, role of fiscal policy. Yet in another sense our focus is broader, because redistributive policies go beyond the government budget-think, for instance, of labor market policies.

We consider economic, political, and behavioral explanations for these differences between the United States and Europe. Economic explanations focus on the variance of income and the skewness of the income distribution before taxes and transfers, the social costs of taxation, the volatility of income, and expected changes in income for the median voter. We conclude that most of these theories cannot explain the observed differences.

We are grateful to our discussants for very useful suggestions. We also thank William Easterly, Benjamin Friedman, Michael Mandler, Casey Mulligan, Roberto Perotti, Andrei Shleifer, Theda Skocpol, and a large number of conference participants for very useful comments. We thank the National Science Foundation for financial assistance through a grant with the National Bureau of Economic Research. Arnaud Devleeschauwer and Jesse Shapiro provided excellent research assistance. 
Before-tax income in the United States has both a higher variance and a more skewed distribution. There is no evidence that the deadweight losses from taxation are lower in Europe. And the volatility of income appears to be lower in Europe than in the United States. However, there is some possibility that middle-class households in the United States have a greater chance of moving up in the income distribution, which would make the median voter more averse to redistribution.

Political explanations for the observed level of redistribution focus on institutions that prevent minorities from gaining political power or that strictly protect individuals' private property. Cross-country comparisons indicate the importance of these institutions in limiting redistribution. For instance, at the federal level, the United States does not have proportional representation, which played an important role in facilitating the growth of socialist parties in many European countries. America has strong courts that have routinely rejected popular attempts at redistribution, such as the income tax or labor regulation. The European equivalents of these courts were swept away as democracy replaced monarchy and aristocracy. The federal structure of the United States may have also contributed to constraining the role of the central government in redistribution.

These political institutions result from particular features of U.S. history and geography. The formation of the United States as a federation of independent territories led to a structure that often creates obstacles to centralized redistributive policies. The relative political stability of the United States over more than two centuries means that it is still governed by an eighteenth-century constitution designed to protect property. As world war and revolution uprooted the old European monarchies, the twentiethcentury constitutions that replaced them were more oriented toward majority rule, and less toward protection of private property. Moreover, the spatial organization of the United States-in particular, its low population density - meant that the U.S. government was much less threatened by socialist revolution. In contrast, many of Europe's institutions were established either by revolutionary groups directly or by elites in response to the threat of violence.

Finally, we discuss reciprocal altruism as a possible behavioral explanation for redistribution. Reciprocal altruism implies that voters will dislike giving money to the poor if, as in the United States, the poor are perceived as lazy. In contrast, Europeans overwhelmingly believe that the 
poor are poor because they have been unfortunate. This difference in views is part of what is sometimes referred to as "American exceptionalism."

Racial discord plays a critical role in determining beliefs about the poor. Since racial minorities are highly overrepresented among the poorest Americans, any income-based redistribution measures will redistribute disproportionately to these minorities. Opponents of redistribution in the United States have regularly used race-based rhetoric to resist left-wing policies. Across countries, racial fragmentation is a powerful predictor of redistribution. Within the United States, race is the single most important predictor of support for welfare. America's troubled race relations are clearly a major reason for the absence of an American welfare state.

\section{The Size and Structure of Redistributive Policies in the United States and Europe}

In this section we review the basic facts about the level of redistribution to the poor in the United States and Europe.

\section{Government Spending}

Table 1 summarizes the magnitude and composition of government spending in Europe and in the United States, using data from the Organization for Economic Cooperation and Development (OECD). In addition to reporting averages for the countries in the European Union, we provide separate data on the United Kingdom (the one EU country with a relatively small government), Germany (the largest EU country), Sweden (as the prototype of a country with an especially large welfare state), and France.

General government spending in the countries in the European Union averages 48 percent of GDP; it is 38 percent in the United Kingdom and 60 percent in Sweden. General government spending in the United States is smaller than any of these, at 36 percent of GDP. The composition of spending is also instructive. The largest differences between the United States and Europe are in transfers to households (including social security) and subsidies. In fact, the sum of these two categories of spending is almost twice as large, as a share of GDP, in Europe as in the United States

1. Lipset (1996). 
Table 1. Composition of General Government Expenditure, 1999a

Percent of GDP

\begin{tabular}{|c|c|c|c|c|c|c|}
\hline \multirow[b]{2}{*}{ Country } & \multirow[b]{2}{*}{ Total } & \multicolumn{2}{|c|}{ Consumption } & \multirow[b]{2}{*}{ Subsidies } & \multirow{2}{*}{$\begin{array}{c}\text { Transfers } \\
\text { and other } \\
\text { social } \\
\text { benefits }^{\mathrm{b}}\end{array}$} & \multirow[b]{2}{*}{$\begin{array}{c}\text { Gross } \\
\text { investment }\end{array}$} \\
\hline & & $\begin{array}{l}\text { Goods } \\
\text { and } \\
\text { services }\end{array}$ & $\begin{array}{c}\text { Wages } \\
\text { and } \\
\text { salaries }\end{array}$ & & & \\
\hline United States & 35.1 & 5.1 & 9.2 & 0.3 & 10.7 & 3.4 \\
\hline European Union ${ }^{\mathfrak{c}}$ & 47.9 & 8.4 & 12.0 & 1.5 & 18.1 & 2.8 \\
\hline France & 51.0 & 10.0 & 13.7 & 1.3 & 20.1 & 3.0 \\
\hline Germany & 47.4 & 10.7 & 8.3 & 1.7 & 20.5 & 1.8 \\
\hline Sweden & 60.2 & 10.3 & 16.7 & 2.0 & 21.1 & 2.5 \\
\hline United Kingdom & 38.3 & 11.0 & 7.4 & 0.6 & 15.7 & 1.0 \\
\hline
\end{tabular}

Source: Authors' calculations based on data from OECD Economic Outlook database, no. 68, 2000 (see appendix B for details)

a. Details may not sum to totals because of excluded categories.

b. Includes social security.

c. Simple average for fourteen EU countries (excludes Luxembourg).

(20 percent versus 11 percent). The difference in transfers and subsidies accounts for 9 percentage points of the 12-percentage-point difference in total spending. Consumption of goods and services and government wages are also higher in Europe, but the difference relative to the United States is much smaller than that for transfers. Public investment is actually higher in the United States than in the average EU country. Of course, military spending is higher in the United States than in Europe (data not shown), even today when U.S. defense spending is low by post-World War II standards. Western Europe since World War II has been a free rider on defense provided by the United States. If the United States had spent less to defend Western Europe and itself from the Soviet threat, the difference in the overall size of government would be even larger.

The OECD offers a different breakdown of government social spending; these data are presented in table 2 for 1995, the latest year for which they are available. In all categories except health, the United States spends a smaller proportion of GDP than the European average. The differences are particularly large in family allowances and unemployment compensation and other labor market programs. By this accounting, social spending in the United States was 16 percent of GDP in 1995, whereas the European average was 25 percent. $^{2}$

2. Total social spending in table 2 is not meant to coincide with the item "Transfers and other social benefits" in table 1. Apart from the fact that the two tables refer to different years, the definitions of the two items differ. For instance, health benefits in table 2 
Table 2. Government Expenditure on Social Programs, 1995

Percent of GDP

\begin{tabular}{|c|c|c|c|c|c|c|}
\hline Country & Total & $\begin{array}{l}\text { Old-age, } \\
\text { disability, } \\
\text { and } \\
\text { survivors' } \\
\text { benefits }\end{array}$ & $\begin{array}{l}\text { Family } \\
\text { benefits }\end{array}$ & $\begin{array}{l}\text { Unemployment } \\
\text { and labor } \\
\text { market } \\
\text { programs }\end{array}$ & $\begin{array}{l}\text { Health } \\
\text { benefits }^{\mathrm{a}}\end{array}$ & Other $^{\mathrm{b}}$ \\
\hline United States & 15.8 & 7.3 & 0.6 & 0.6 & 6.3 & 1.0 \\
\hline European Union ${ }^{\mathfrak{c}}$ & 25.4 & 12.4 & 2.1 & 3.2 & 5.9 & 1.8 \\
\hline France & 30.1 & 14.1 & 2.6 & 3.1 & 8.0 & 2.3 \\
\hline Germany & 28.0 & 12.5 & 2.0 & 3.7 & 8.1 & 1.6 \\
\hline Sweden & 33.0 & 14.8 & 3.9 & 4.7 & 5.9 & 3.8 \\
\hline United Kingdom & 22.5 & 10.6 & 2.4 & 1.3 & 5.7 & 2.5 \\
\hline
\end{tabular}

Source: Authors' calculations based on data from OECD Social Expenditure database, 1999.

a. Also includes inpatient care, ambulatory medical services, and pharmaceutical goods.

b. Includes expenditure on occupational injury and disease benefits, sickness benefits, housing benefits, and benefits to lowincome households.

c. Simple average for the fifteen EU countries.

Consider the other non-European OECD countries (not shown in the tables). The size of government in Canada (46 percent of GDP) is similar to that in France and slightly below the European average. Japan and Australia have governments that are smaller than Canada's (42 and 36 percent of GDP) but still slightly larger than the U.S. government, whereas New Zealand's government, at 41 percent of GDP, is roughly midway between those of the United States and Europe. The average for the nonEuropean, non-U.S. OECD countries falls somewhere in between the United States and Europe. Thus, in comparing the United States and Europe, we are comparing two extremes in the OECD group.

Differences in the overall size of government or even in the size of transfer programs are only indirectly related to the extent of redistribution from the rich to the poor. For instance, the social security system involves flows from the young to the old as well as from the rich to the poor. Nevertheless, it is uncontroversial that a predominant share of public goods, and especially transfers, favors the poor disproportionately.

\section{The Structure of Taxation}

Table 3 summarizes the composition of government revenue in Europe and the United States. The most striking differences are in social security

includes the wages of government workers in the health sector, which would be included under "Wages and salaries" in tabie 1. 


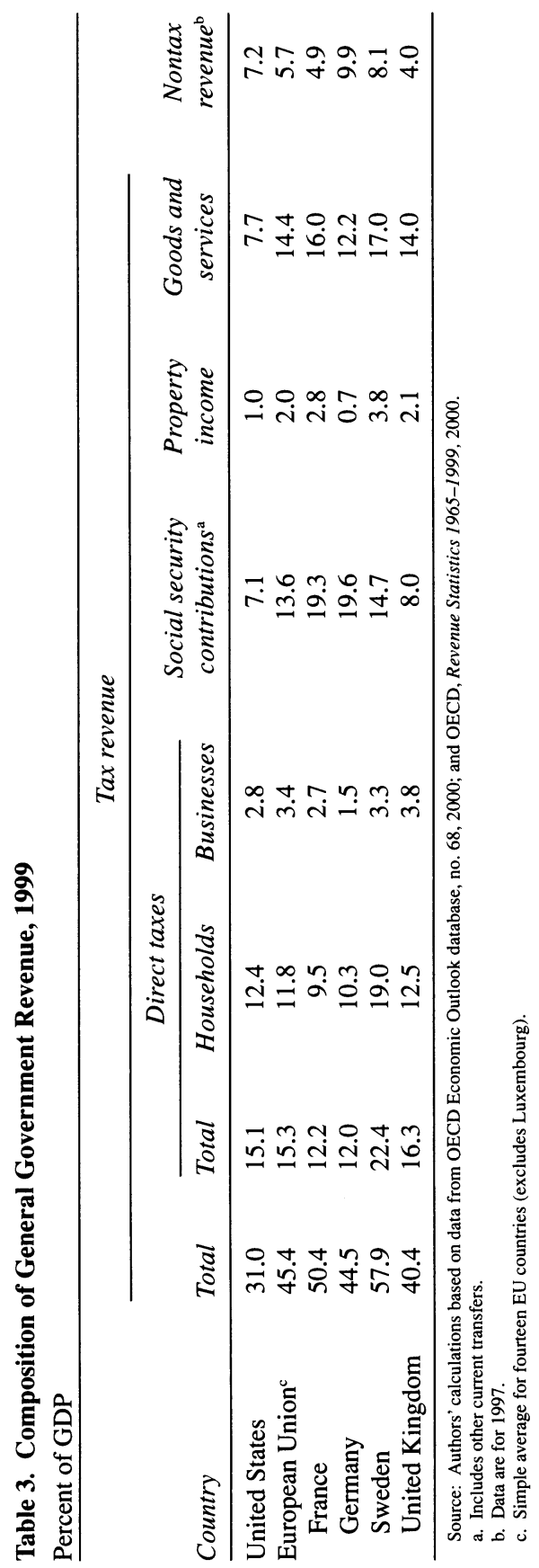


contributions and taxes on goods and services. However, there are important differences in the structure of taxation even within Europe. ${ }^{3}$ Our concern here is with the tax burden of the rich relative to that of the poor. To calculate a precise measure of the progressivity of the tax system across all these countries would require an entire paper (at least) devoted to unraveling the intricacies of the different tax codes. Although such a task is beyond the scope of this paper, a simple attempt is made in figure 1. We assembled data on the different income tax brackets of the European countries and took a cross-country average. We then subtracted this average from the corresponding federal income tax brackets in the United States; figure 1 plots that difference. Thus, for a given level of income, a positive value in the figure implies that the marginal tax rate in the United States exceeds the European average, and a negative value indicates the opposite. The figure shows that marginal tax rates in the United States are higher than in Europe for low levels of income (up to about 50 percent of the average worker's wage) and lower for higher levels of income. Also, the difference between the United States and Europe becomes larger in absolute value as income rises. In short, the income tax system is much more progressive in Europe than in the United States. ${ }^{4}$

\section{Historical Trends in the Size of Government}

Understanding the reasons for these striking differences between the United States and Europe requires that we know something of the history of redistribution in both regions. In particular, we want to know when the size of government, and especially the size of the welfare state in Europe, diverged from that in the United States. Did the two share a similar size of government for a while and then diverge, or has the difference always been present?

Table 4 provides a clear answer: from the very beginning of the expansion of the public sector in the late nineteenth century, the United States and Europe show very distinct patterns. Although the ratio of welfare

3. In fact, a hotly debated issue within the European Union is precisely the harmonization of tax structures across members.

4. In other countries with federal systems, such as Germany, the structure of taxation also entails automatic redistribution from richer to poorer regions. This is not so, or at least not to the same extent, across U.S. states. Some geographical redistribution does, however, occur within school districts in the United States. See Oates (1999) and the references cited therein. 
Figure 1. Difference between U.S. and EU Marginal Income Tax Rates, 1999-2000

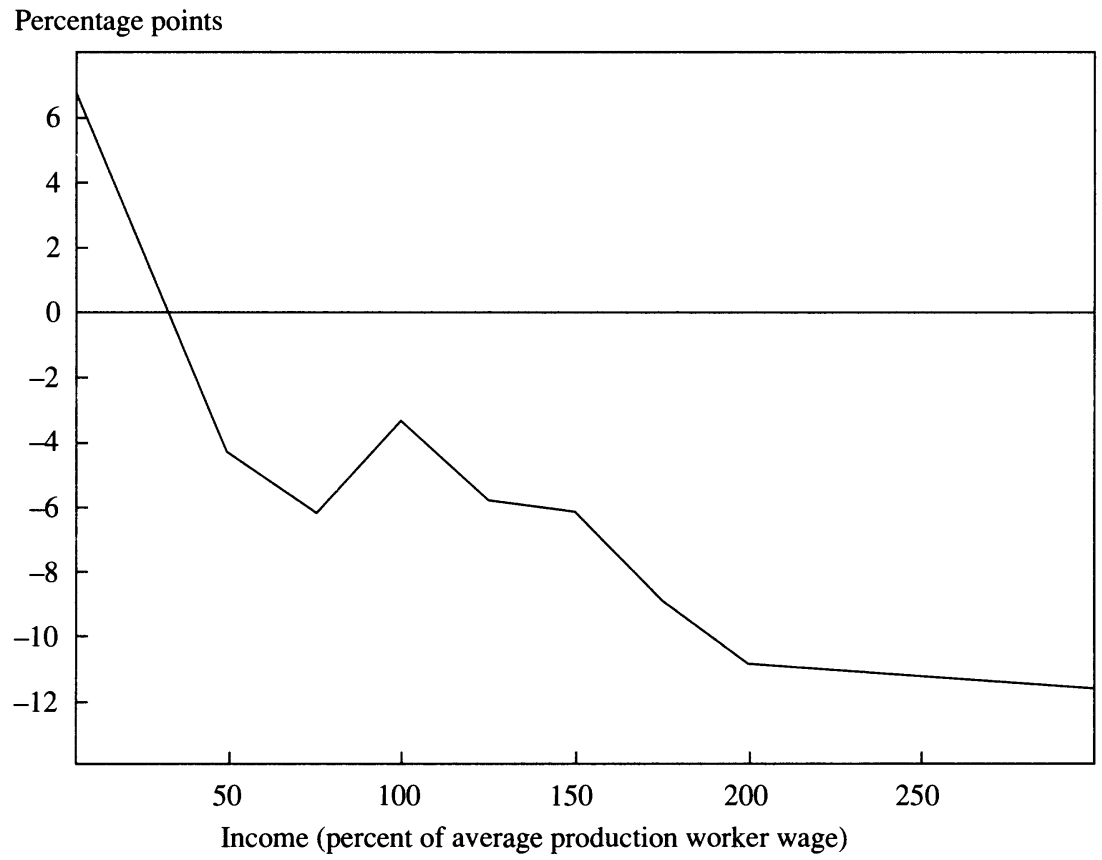

Source: Authors' calculations based on data from OECD, Taxing Wages, 1999-2000, 2001.

a. Years are fiscal years. U.S. marginal income tax rate minus a simple average of rates for fourteen EU countries (excludes Denmark) at each income level.

spending was already high at the end of the nineteenth century, the absolute difference grew as the welfare state expanded both in Europe and in the United States, especially in the 1960s and 1970s. The observation that the difference is of long standing is important, because it allows us to exclude explanations of the difference that are specific to a certain period or event.

\section{Income Support Policies and Safety Nets}

In addition to the aggregate data provided above, it is useful to compare specific programs for income support and safety nets. We consider Germany, Sweden, and the United States, and we focus on a representative household. We determine the extent to which existing programs and their provisions can be beneficial to such a household when it experiences 
Table 4. Government Expenditure on Subsidies and Transfers, 1870-1998a

Percent of GDP

\begin{tabular}{|c|c|c|c|c|c|c|}
\hline Country & 1870 & 1937 & 1960 & 1970 & 1980 & 1998 \\
\hline United States & 0.3 & 2.1 & 5.0 & 7.5 & 10.4 & 11.0 \\
\hline European Union ${ }^{\mathrm{b}}$ & 0.9 & 6.8 & 10.7 & 13.2 & 17.9 & 19.0 \\
\hline France & 1.1 & 7.2 & 14.1 & 14.9 & 18.4 & 21.5 \\
\hline Germany & 0.5 & 7.0 & 13.7 & 15.4 & 20.4 & 22.1 \\
\hline Sweden & 0.7 & $\ldots$ & 8.1 & 12.1 & 21.1 & 23.8 \\
\hline United Kingdom & $\ldots$ & 10.3 & 9.2 & $\ldots$ & $\ldots$ & 16.4 \\
\hline \multicolumn{7}{|l|}{ Memorandum: } \\
\hline Difference, EU-U.S. & 0.6 & 4.7 & 5.7 & 5.6 & 7.6 & 7.8 \\
\hline
\end{tabular}

increased hardship. We examine the costs of raising a child, of sickness, of disability, and of extreme poverty (see appendix B for data sources). We discuss unemployment policies in the context of more general labor market regulations in the next subsection.

Our representative household is composed of two adults and two children. The adults, both aged thirty-five, are average production workers with fifteen years of work experience. The two children are aged eight and twelve, to take a benchmark often used by social security administrations. The monthly before-tax earnings of an average production worker in the three countries, in 1999 dollars adjusted for purchasing power parity (PPP), are $\$ 2,498$ in the United States, $\$ 2,561$ in Germany, and $\$ 1,880$ in Sweden.

FAMILY BENEFITS. Child benefits are available in Germany and Sweden for every parent, without regard to income, until the child reaches eighteen (in Germany) or sixteen (in Sweden), but those limits can be extended if the child pursues higher education. By contrast, family allowances do not exist in the United States. ${ }^{5}$ However, special allowances for children of low-income families are allocated under the Temporary Assistance for Needy Families program (TANF, which replaced the Aid to Families with Dependent Children, or AFDC, program in the mid-1990s), as discussed below. To summarize, each child entitles the representative

5. The United States does have a fixed child tax credit ( $\$ 600$ per child in 2001 ), and the amount of the earned income tax credit increases with the number of children in the family (but is available only to low-income workers). 
household to monthly benefits (again in 1999 PPP-adjusted dollars) of $\$ 136$ in Germany, \$87 in Sweden, and zero in the United States.

HEALTH CARE. The public health care systems of Germany and Sweden also differ significantly from that of the United States. Both Germany and Sweden provide universal coverage, with unlimited benefits including payments of doctors' fees, hospitalization, and the cost of pharmaceutical products. The United States, on the other hand, relies on two programs, Medicare and Medicaid, which target mainly the elderly and low-income households, respectively. If one of the members of our representative U.S. family became sick and had to visit a doctor or stay in a hospital, he or she would not be eligible for public funds or services (although a large fraction of employers offer health insurance as part of their compensation package). In contrast, the representative German or Swedish household would have most of these expenses covered by the public health care program. A small part of the cost is borne by the household in the form of a deductible. In Germany the household pays a deductible of $\$ 9$ for each day of hospitalization; in Sweden the hospitalization deductible is $\$ 8$, and in addition there is a deductible of $\$ 10$ to $\$ 14$ for medical treatment, again in 1999 PPP dollars.

SICKNESS AND ACCIDENTAL INJURY BENEFITS. Sickness benefits are intended to replace the loss of earnings due to sickness of a household's income earners. Once again, the coverage and the extent of benefits differ radically between the United States and the two European countries examined here. Indeed, only five states in the United States offer any kind of sickness benefit (there is no federal benefit), whereas German and Swedish legislation guarantees benefits for all persons in paid employment; these benefits replace up to 70 percent and 80 percent of gross earnings, respectively. If the head of our representative U.S. household fell sick (and was fortunate enough to live in one of the five states that offer sickness benefits), he or she would receive (in 1999 PPP dollars) between $\$ 452$ and $\$ 1,576$ a month (between 18 and 63 percent of the average wage); the representative household head in Germany would receive $\$ 1,793$ a month, and his or her Swedish counterpart would receive $\$ 1,504$ a month. The U.S. household's benefits would last for a maximum of fifty-two weeks, whereas those of the German household would expire only after seventyeight weeks, and those of the Swedish household could continue indefinitely. 
Accidental injuries occurring in the enterprise or in connection with the working situation of the employee are covered in all three countries, including every state in the United States, and these benefits are quite comparable. German and Swedish workers who suffer on-the-job injuries see their income replaced according to the amounts allocated by sickness benefits, whereas American workers receive the equivalent of two-thirds of their average weekly earnings, up to a maximum of $\$ 270$ to $\$ 714$ a week, depending on the state.

DISABILITY BENEFITS. All three countries also have provisions to replace income lost due to inability to engage in any gainful activity. Participation is compulsory in all three systems, and coverage is based on work history. The United States and Germany require at least five years of employment before a worker can receive benefits; in Sweden the requirement is three years. But the extent of coverage differs dramatically across the three countries. Whereas in the United States the disability pension is based on the worker's average monthly earnings, the Swedish scheme provides a basic minimum pension, augmented by an incomebased supplementary pension, care allowances, and handicap allowances; German pensions are computed using the level of income and the number of years of contribution. For the representative production worker, disability benefits amount to $\$ 1,063$ in the United States and $\$ 1,504$ in Sweden (again in 1999 PPP dollars). These correspond to 43 percent and 80 percent of the average wage, respectively.

POVERTY RELIEF. In all three countries, certain government programs are directed at persons who are unable to support themselves but are not covered under the schemes described above. These persons may fail to meet eligibility criteria because of insufficient past contributions, or their incomes may be too low to allow them to take part in insurance schemes. The programs that provide these pure cash transfers differ in structure across the three countries. Germany and Sweden rely on unlimited and unconditional plans (called Sozialhilfe and Socialbidrag, respectively), which are meant primarily to alleviate poverty. Additional plans covering the costs of housing and heating are also available for German residents. The United States, on the other hand, offers an array of plans targeting different groups in the population. Supplemental Security Income (SSI) targets aged, blind, and disabled persons with annual gross income below about $\$ 14,500$; the federal payment can be augmented by a state supple- 
ment. The TANF program, mentioned above, is limited to two years of assistance; recipients who are able to work must find employment at the end of that period. Other plans, such as those for food and nutrition assistance and those for housing assistance, also provide relief to low-income households.

A representative U.S. household that has zero income and has exhausted all other claims to regular benefits could be eligible for $\$ 1,306$ in monthly benefits under these programs $(\$ 726$ from SSI, or 29 percent of the average monthly wage, and $\$ 580$ from TANF, or 23 percent of the average wage). ${ }^{6}$ Its German counterpart would be eligible to receive $\$ 1,008$ a month, and its Swedish counterpart $\$ 892$ a month (39 percent and 47 percent of the average wage, respectively, again in 1999 PPP-adjusted dollars). These amounts do not include benefits available under additional programs such as housing allowances.

\section{Labor Market Policies}

Not all redistributive policies involve government expenditure. Legislation in several other areas also determines the degree of government involvement in redistributing income. An obvious case is that of labor market policies. Labor regulations such as those that set a minimum wage may keep real wages higher than they would be otherwise. ${ }^{7}$ Table 5 summarizes the available data on minimum wages in Europe and the United States. The data are from several different sources, but all tell a very similar story. In the European Union the minimum wage is 53 percent of the average wage, against 39 percent in the United States. In France the minimum wage is around 65 percent of the average manufacturing wage, compared with 36 percent in the United States.

Table 6 reports various other measures of labor market regulation, using data assembled by Stephen Nickell and Richard Layard. ${ }^{8}$ Although a fair amount of variation is observed within Europe, on all measures the United States scores lower (often much lower) than the European average. The first column of the table reports an index compiled by the OECD that combines several aspects of legislation designed to protect workers in

6. This value refers to the state of Massachusetts, which pays the highest TANF benefits among states in the program.

7. One may argue, correctly, that in many cases labor regulations end up redistributing in favor of the unionized or otherwise "protected" segment of the labor force, at the expense of other workers.

8. Nickell and Layard (1999); Nickell (1997). 
Table 5. Comparing the Minimum Wage in the United States and the European Union

Percent

\begin{tabular}{lccc}
\hline & \multicolumn{3}{c}{ Ratio of minimum wage to } \\
\cline { 2 - 4 } Country & \multicolumn{3}{c}{\begin{tabular}{c} 
Average manufacturing wage \\
\cline { 2 - 4 }
\end{tabular}} \\
\cline { 2 - 4 } & $(1991-94)$ & $\begin{array}{c}\text { OECD } \\
(1997)\end{array}$ & $\begin{array}{c}\text { Eurostat }^{\mathrm{c}} \\
(1999)\end{array}$ \\
\hline United States & 39 & 36 & 34 \\
European Union & 53 & 56 & 53 \\
France & 50 & 68 & 63 \\
Germany & 55 & $\ldots$ & $\ldots$ \\
Sweden & 52 & $\ldots$ & 44 \\
United Kingdom & 40 & $\ldots$ & 4
\end{tabular}

Source: Nickell and Layard (1999); OECD, Employment Outlook, 2000; authors' calculations based on data from Eurostat, Minimum Wages in the European Union, 2001.

a. As reported in Nickell and Layard (1999). EU average is for thirteen countries (excludes Greece and Luxembourg).

b. EU average is for Belgium, France, Greece, Luxembourg, the Netherlands, Portugal, and Spain.

c. EU average is for Belgium, France, Greece, Ireland, Luxembourg, the Netherlands, Portugal, Spain, and the United Kingdom.

the workplace (see appendix B). The minimum score (representing the least protection) is zero and the maximum 10. The second column reports an index of employment protection (that is, restrictions on the ability of enterprises to terminate employees), with 20 indicating the strictest protection. On the first measure the United States has a score of zero, and on the second a score of one. The next three columns report measures of minimum annual leave and the level and duration of unemployment com-

Table 6. Labor Market Regulation in the United States and the European Union

Units as indicated

\begin{tabular}{|c|c|c|c|c|c|}
\hline \multirow[b]{2}{*}{ Country } & \multirow[b]{2}{*}{$\begin{array}{c}\text { Labor } \\
\text { standards, } \\
\text { 1985-93 }^{\mathrm{a}} \\
\text { (index) }\end{array}$} & \multirow[b]{2}{*}{$\begin{array}{c}\text { Employment } \\
\text { protection, } \\
1990^{\circ} \\
\text { (index) }\end{array}$} & \multirow[b]{2}{*}{$\begin{array}{l}\text { Minimum } \\
\text { annual } \\
\text { leave, } 1992 \\
\text { (weeks) }\end{array}$} & \multicolumn{2}{|c|}{ Unemployment benefit } \\
\hline & & & & $\begin{array}{c}\text { Replacement } \\
\text { ratio, } \\
\text { 1989-94 } \\
\text { (percent) }\end{array}$ & $\begin{array}{c}\text { Duration, } \\
\text { 1989-94 } \\
\text { (years) }\end{array}$ \\
\hline United States & 0 & 1 & 0 & 50 & 0.5 \\
\hline European Union ${ }^{c}$ & 5 & 14 & 4 & 59 & 2.6 \\
\hline France & 6 & 14 & 5 & 57 & 3.0 \\
\hline Germany & 6 & 15 & 3 & 63 & 4.0 \\
\hline Sweden & 7 & 13 & 5 & 80 & 1.2 \\
\hline United Kingdom & 0 & 7 & 0 & 38 & 4.0 \\
\hline
\end{tabular}

Source: Nickell and Layard (1999); Nickell (1997).

a. Combines several measures of labor market regulation and ranges from 0 to 10 , with 10 the maximum

b. Measures the strength of legal restrictions on hiring and firing and ranges from 0 to 20, with 20 the maximum.

c. Simple average of thirteen EU countries (excludes Greece and Luxembourg). 
pensation. On all three measures the U.S. score is below that of the European Union as a whole and below that of any of the individual European countries listed (except that the U.K. level of unemployment compensation is lower).

Scores on these measures for a group of non-European, non-U.S. OECD countries (Australia, Canada, Japan, and New Zealand; data not shown) lie somewhere in between those of the United States and continental Europe. On some measures these countries may be closer to the United States, and on others closer to Europe. Overall, however, the United States and Europe appear to be polar extremes.

\section{Has It Worked?}

The consequences of the greater expansion of the welfare state in Europe than in the United States are important, but well beyond the already broad scope of this paper. We want to explain the causes of this difference, not its consequences. Nevertheless, it is worth pausing to briefly characterize the conventional wisdom (if there is any) on this issue. Needless to say, the question of the impact of a large welfare state is difficult to answer and loaded with ideological biases. We think that a fair and relatively uncontroversial assessment of the effect of these different levels of redistributive policies in the broadest possible terms is as follows.

As Vito Tanzi and Ludger Schuknecht forcefully argue in a recent study of the growth of government, averages of several key social indicators such as health measures, life expectancy, and educational achievement are not that different between countries with a large government like those in continental Europe and countries with a small government like that in the United States. ${ }^{9}$ On the other hand, a large body of research has shown that after-tax income inequality is lower in countries with larger governments and, in particular, in countries with higher social spending. ${ }^{10}$ As is well known, comparing inequality and poverty rates across countries is a minefield. However, it is quite clear that after-tax income inequality is relatively low in the Nordic countries, intermediate in central and southern Europe, higher in the United Kingdom, and higher still in the United States. ${ }^{11}$

9. Tanzi and Schuknecht (2000).

10. See, for instance, Atkinson (1995).

11. This picture emerges, for instance, from the detailed studies by Atkinson (1995). 
When one compares the distribution of disposable income across population deciles in the United States and Europe, a striking and interesting difference is the much lower proportion of income accruing to the lowest decile in the United States. That is, the greater inequality in the United States does not stem from the top decile being particularly wealthy relative to the median, so much as from the bottom decile being particularly poor. For instance, in the 1980s the average income among the lowest decile was about a third of the median in the United States, compared with more than 55 percent in many European countries, including France, and more than 60 percent in several Nordic countries. ${ }^{12}$ Another way of looking at this is to compute the fraction of the population with incomes below 50 percent of the median. (Many European countries use this as a definition of the poverty line.) Depending on the criteria used, this fraction was around 17 to 18 percent in the United States in the 1980s, against values of 5 to 8 percent in Sweden and Germany. ${ }^{13}$

In the 1990s income inequality increased sharply in the United Kingdom and somewhat less sharply in the United States. In the continental European countries, changes in income inequality in the last decade were smaller. It would appear that, because of a smaller emphasis on policies that redistribute toward the poor, the bottom decile of the income ladder in the United States is less well off than the bottom decile in European countries. That is, the U.S. poor are really poor. ${ }^{14}$

How much the reduction in inequality achieved by a more redistributive government "costs" in terms of slower growth because of higher taxation, more intrusive regulation, and so forth is a large and difficult question that we cannot even begin to answer here. Assar Lindbeck provides an excellent and exhaustive discussion of this issue for Sweden. ${ }^{15}$ His conclusion is that in the long run the trade-off between redistribution and growth is rather steep. In 1970, before the explosion of its welfare state, Sweden had an income per capita equivalent to 115 percent of that in the

12. Atkinson (1995, pp. 49-51).

13. Atkinson (1995, p. 90).

14. It should be clear, however, that this inverse relationship between inequality and the size of government is not monotonic. That is, certain countries are much more successful than others in reducing inequality for a given amount of social spending: the welfare state in different countries has had different degrees of success in reaching the truly needy. One problem is that, in certain countries (Italy being a perfect example), welfare spending is too biased in favor of pensions. See Boeri (2000).

15. Lindbeck (1997). 
average OECD country - the fourth-highest of all. By 1995, however, Sweden's income per capita was only 95 percent of the OECD average, and Sweden had fallen to sixteenth place. One may wonder whether the trade-off is so steep at levels of social protection less extreme than Sweden's. Other countries with extended welfare states have not done as poorly as Sweden. Also, certain aspects of redistributive policies, such as a well-functioning public education system, may foster human capital accumulation. A related issue is the cost in terms of employment formation and growth of labor protection, but this is another immense topic that would require not one but several papers to do it justice.

\section{Charity and the Private Provision of Welfare}

The preceding evidence makes it clear that European countries provide more public welfare than the United States. But Americans engage in more private provision of welfare (that is, charity) than do Europeans. As private citizens, Americans appear to give more of their time and their money to the poor than do Europeans.

We use the World Values Survey to calculate the share of adults in each of several European countries who are members of charitable organizations. The World Values Survey is a collection of surveys where the same questions are asked in different countries in different years. Between 600 and 2,000 people are interviewed in each country; appendix B provides details on the countries and survey years. Although membership in charitable organizations is an imperfect measure of the time contribution to charity (it does not measure the intensity of involvement), it is one of the best measures available. In the United States, 11 percent of respondents say that they participated in a charitable group over the last year; the average for the European countries in the survey is 4 percent. The European country with the highest proportion of membership in private charities is the Netherlands, with almost 9 percent of respondents saying that they participate. At the other end of the spectrum is Denmark, where 2 percent of individuals claim to have participated in these activities.

This work corroborates the large literature on private charity in the United States. For example, the U.K. National Council for Volunteer Organizations and the not-for-profit group United for a Fair Economy document that charitable contributions in the United States totaled $\$ 190$ billion in 2000 , or $\$ 691$ a person. This compares with reported contributions per 
capita of $\$ 141$ in the United Kingdom and $\$ 57$ for Europe as a whole. Notably, a large fraction of American donors make charitable contributions even though they take only the standard deduction on their income taxes. This means that, for many Americans, contributions are not being driven by the tax deductibility of charitable donations. Theda Skocpol, Marshall Ganz, and Ziad Munson document the national coverage of the many U.S. volunteer groups who provide a rich variety of forms of assistance. ${ }^{16}$

These results suggest, but hardly prove, two implications. First, public provision of welfare in part crowds out private charity. As argued by Glaeser and Andrei Shleifer, if government transfers to particular individuals fall as private donations rise, these transfers will reduce the incentive for private charity. ${ }^{17}$ These results also suggest that Europe's more generous provision of welfare does not stem from a greater innate endowment of altruism in Europe.

\section{Theory and Discussion}

In this section we present a brief formal model on the determinants of the level of redistribution. ${ }^{18}$ We model the welfare system as a schedule of transfers that is indexed with a single parameter: the tax rate on income $\tau$. In this system each individual receives net transfers equal to $\tau(\delta \hat{Y}-Y)$, where $Y$ is the individual's income, $\hat{Y}$ is average income in the country, and $\delta<1$ represents the waste involved in redistribution. This welfare system is self-financing, in the sense that the average payment in the country is equal to zero. The parameter $\delta$ is meant to capture a wide range of possible inefficiencies related to government, such as administrative costs and politically motivated spending on programs with little social value. It can also capture the welfare losses due to tax distortions; in this case $\delta$ should be a function of $\tau$, to capture the fact that social welfare losses generally rise proportionately to the square of the tax rate, but for simplicity we assume that $\delta$ and $\tau$ are independent.

16. Skocpol, Ganz, and Munson (2000). Although Putnam (2000) argues that civic voluntarism has declined in the United States, we do not address this decline here. Rather we focus on the differences over space, not over time.

17. Glaeser and Shleifer (2001b).

18. The logic of this model is closely tied to the work of Benabou and Ok (2001), Perotti (2000), Picketty (1995), and many others, and this work should be seen as a synthesis, not as a new model. 
The timing of the model is such that, in the first period, individuals receive income equal to $Y_{0}$ and choose $\tau$ for the second period. The firstperiod tax rate was already fixed, and we do not model consumption or saving during this period. First-period income serves just as a signal for second-period income, and its distribution is captured by a density function $g(\cdot)$.

In the second period, incomes are revealed and redistribution and consumption occur. Income in the second period, $Y\left(Y_{0}, \varepsilon\right)$, equals $(1-\theta) Y_{0}+$ $\theta\left[\mu\left(Y_{0}\right)+\varepsilon\right]$. The parameter $\theta$ captures the extent of income mobility: a low value of $\theta$ means that income in the second period will be almost equal to income in the first period. The variable $\mu\left(Y_{0}\right)$ is the mean of the second-period income shock, which is a weakly increasing function of prior income. This function will also capture the extent of income mobility. For example, if $\mu\left(Y_{0}\right)=Y_{0}$, then incomes will be much more fixed than if $\mu\left(Y_{0}\right)$ is constant across individuals. The term $\varepsilon$ represents a mean zero disturbance term that is assumed to be orthogonal to the other terms and distributed with density $f(\cdot)$.

Individuals consume all of their second-period income (net of redistribution) and receive utility from personal consumption equal to $U\left((1-\tau)\left\{(1-\theta) Y_{0}+\theta\left[\mu\left(Y_{0}\right)+\varepsilon\right]+\tau \delta \hat{Y}\right\}\right)$. Thus, expected utility (as of the first period) from second-period personal consumption equals

$$
\int_{\varepsilon} U\left((1-\tau)\left\{(1-\theta) Y_{0}+\theta\left[\mu\left(Y_{0}\right)+\varepsilon\right]\right\}+\tau \delta \hat{Y}\right) f(\varepsilon) d \varepsilon .
$$

We assume that people care about the consumption of others as well as their own. For tractability we measure altruism as follows: each person puts a weight $\alpha\left(Y_{0}\right)$ on the utility he or she derives from the private consumption utilities of other people; this term reflects interpersonal altruism, and we assume that $\alpha\left(Y_{0}\right) \geq 0$. Total expected utility from private consumption and interpersonal utility equals

$$
\begin{aligned}
& \int_{\varepsilon} U\left((1-\tau)\left\{(1-\theta) Y_{0}+\theta\left[\mu\left(Y_{0}\right)+\varepsilon\right]\right\}+\tau \delta \hat{Y}\right) f(\varepsilon) d \varepsilon+ \\
& \int_{Y_{0}} \alpha\left(Y_{0}\right) \int_{\varepsilon} U\left((1-\tau)\left\{(1-\theta) Y_{0}+\theta\left[\mu\left(Y_{0}\right)+\varepsilon\right]\right\}+\tau \delta \hat{Y}\right) f(\varepsilon) g\left(Y_{0}\right) d \varepsilon d Y_{0} .
\end{aligned}
$$

We represent the political process as the social choice problem of maximizing a weighted sum of all people's expected utilities. The political 
arrangement is captured by the weights that different people get in the political process. In particular, each person receives a weight of $\lambda\left(Y_{0}\right)$ in the social choice problem, where $\lambda\left(Y_{0}\right) \geq 0$. This weight is a function of their initial endowment. For example, under a system of majority rule when preferences for redistribution (the level of $\tau$ ) have a single peak, the social choice problem will assign weight only to the tastes of the individual with median income. In the proposition we will assume $\lambda\left(Y_{0}\right)=1$ $+\lambda\left(\hat{Y}-Y_{0}\right)$, which gives us a single parameter, $\lambda$, that reflects the extent to which the preferences of the poor are internalized by the political process.

Thus the total social welfare function becomes

$$
\begin{aligned}
& \int_{Y_{0}}\left[\alpha\left(Y_{0}\right)+\lambda\left(Y_{0}\right)\right] \times \\
& \int_{\varepsilon} U\left((1-\tau)\left\{(1-\theta) Y_{0}+\theta\left[\mu\left(Y_{0}\right)+\varepsilon\right]\right\}+\tau \delta \hat{Y}\right) f(\varepsilon) g\left(Y_{0}\right) d \varepsilon d Y_{0},
\end{aligned}
$$

and the optimal amount of redistribution will satisfy the first-order condition

$$
\begin{aligned}
& \int_{Y_{0}}\left[\alpha\left(Y_{0}\right)+\lambda\left(Y_{0}\right)\right] \times \\
& \int_{\varepsilon}\left[\delta \hat{Y}-Y\left(Y_{0}, \varepsilon\right)\right] U^{\prime}\left[(1-\tau) Y\left(Y_{0}, \varepsilon\right)+\tau \delta \hat{Y}\right] f(\varepsilon) g\left(Y_{0}\right) d \varepsilon d Y_{0}=0 .
\end{aligned}
$$

The following proposition captures the role of altruism or political power:

Proposition 1: If $\lambda\left(Y_{0}\right)=1+\lambda\left(\hat{Y}-Y_{0}\right)$, and $\alpha\left(Y_{0}\right)=\alpha_{0}+\alpha\left(\hat{Y}-Y_{0}\right)$, and the level of $\tau$ that maximizes social welfare is between 0 and 1 , then the level of redistribution is rising in both $\alpha$ and $\lambda$.

This proposition is unsurprising, but it highlights the two factors that will probably be most important in driving geographic differences in redistribution. First, factors that reduce altruism toward the poor will reduce redistribution. Second, factors that increase the political power of the poor will increase redistribution.

This proposition suggests two broad explanations for why redistribution might differ between the United States and Europe. First, it might be that differing political structures lead the level of $\lambda$ to be higher in Europe; that is, the poor have more political representation there. One 
such difference is the proportional representation that exists in several European countries, which may make it easier for parties focusing on the poorest citizens to survive. Another is that the U.S. Constitution puts considerable brakes on democracy in ways that European institutions do not. Certain U.S. institutions that are not democratic have veto rights over redistribution in some contexts. For example, the U.S. Supreme Court ruled the income tax to be illegal in the 1890 s, despite its earlier use during the Civil War.

The second broad explanation is that $\alpha$ might be different in the United States and Europe. This could be true for several reasons. Most obviously, if altruism between races is limited, ${ }^{19}$ we might expect that the greater racial heterogeneity in the United States would lead to a lower desire of the median voter, who is white, to give to poor persons of another color. More subtly, it may be that Americans are more likely to associate poverty with laziness and to consider the poor unworthy of assistance. We discuss these issues later.

We now turn to the economic model of selfish redistribution and majority rule. This model assumes that there is no altruism and that the level of redistribution is determined by the preferences of the median voter. In this extreme model the optimization problem becomes

$$
\int_{\varepsilon} U\left((1-\tau)\left\{(1-\theta) Y_{\text {Med }}+\theta\left[\mu\left(Y_{\text {Med }}\right)+\varepsilon\right]\right\}+\tau \delta \hat{Y}\right) f(\varepsilon) d \varepsilon,
$$

where $Y_{M e d}$ is the income of the median voter, and this yields the derivative

$$
\int_{\varepsilon}\left(\delta \hat{Y}-\left\{(1-\theta) Y_{\text {Med }}+\theta\left[\mu\left(Y_{\text {Med }}\right)+\varepsilon\right]\right\}\right) U^{\prime}[Y(\varepsilon)] f(\varepsilon) d \varepsilon .
$$

Inspection of equation 6 yields the following result, which is well known in the literature:

Proposition 2: When $\theta=0$, the median voter will redistribute if and only if $\delta>Y_{M e d} / \hat{Y}$, and the median voter will demand complete redistribution when that condition holds.

19. As in Becker (1957). 
Thus, when there is no income uncertainty and no altruism, the median voter goes to a corner solution. ${ }^{20}$ The absence of income uncertainty $(\theta=0)$ can also be interpreted as suggesting a static model where income is known at the time that redistribution is chosen.

In general, two things determine whether the median voter demands redistribution. First, if the social welfare losses inherent in taxation are quite high (that is, $\delta$ is low), redistribution is unlikely. Second, if the income distribution is quite skewed, $Y_{\text {Med }}$ will be low relative to $\hat{Y}$, and redistribution is more likely.

When there is income uncertainty, and when levels of redistribution are set before income levels are revealed, we are much more likely to find an interior solution for the level of redistribution. To concentrate on income dynamics, we persist in examining the median voter model with no altruism. In this case equation 6 will be set to zero when there is an interior solution, and differentiating this first-order condition provides the following comparative statics:

\section{Proposition 3:}

(a) If the coefficient of relative risk aversion is less than one, the level of redistribution will fall with $\mu\left(Y_{\text {Med }}\right)$ and rise with $\delta$.

(b) If the variance of $\varepsilon$ is small, and expected income growth for the median voter is strictly positive, redistribution will fall with $\theta$.

(c) If $\mu\left(Y_{\text {Med }}\right)=\delta \hat{Y}$ and expected income growth is weakly negative, redistribution will rise with $\theta$.

Proposition 3a tells us that redistribution will fall as the median voter's expected income in the second period rises (holding average income constant). The comparative static analysis for $\delta$ tells us that redistribution declines when it creates more deadweight loss. Proposition $3 b$ tells us that when income shocks have a positive mean for the median voter, greater income mobility leads to a decreased desire for redistribution. This

20. In this formulation, optimization gives us a corner solution because waste is independent of the tax rate. In the more general model, the median voter chooses an interior solution for the tax rate that sets the marginal benefits from an additional dollar of welfare spending equal to the marginal social loss from waste. Proposition 2 is a special case of Meltzer and Richard (1981). Alesina and Rodrik (1994) and Persson and Tabellini (1994) develop this redistribution model in a growth context. 
result is closest to the work of Ronald Benabou and Efe Ok, ${ }^{21}$ who show that expected income growth for the median voter limits the demand for redistribution.

Proposition $3 \mathrm{c}$ tells us that the impact of income mobility will increase the demand for redistribution if income shocks have a negative mean. When income shocks have a zero mean, risk aversion means that greater income mobility leads to more demand for redistribution. One can also interpret this result as a variant on John Rawls, ${ }^{22}$ who argued that risk aversion provides a justification for welfare policies. If there is no heterogeneity of first-period income, so that all people have the same tastes, a greater value of $\theta$ implies a greater variance of second-period income. This interpretation suggests that countries with high before-tax income inequality will have more redistribution.

Overall, the relationship between income mobility and redistribution is complicated. More mobility leads to less redistribution if, as in the case of Benabou and Ok, expected income shocks move the median voter up the income distribution. However, if expected income shocks have a zero mean, risk aversion means that more mobility leads to greater demand for redistribution.

\section{Empirical Evidence}

For purposes of testing the above propositions, we sort the possible explanations of the extent of redistribution into three groups, which we label (somewhat imprecisely) economic, political, and behavioral explanations.

\section{Economic Explanations}

BEFORE-TAX INCOME INEQUALITY. Propositions 2 and 3 suggest that redistribution will be higher in Europe if before-tax income inequality is higher there, or if the income distribution is more likely to be highly skewed. We noted above that after-tax income inequality is higher in the United States. Nevertheless, it is possible that government intervention in

21. Benabou and Ok (2001).

22. Rawls (1971). 
Europe is so widespread that it reverses a basic, underlying pattern of higher before-tax inequality.

The standard source on before-tax income inequality is the database compiled by Klaus Deininger and Lyn Squire. ${ }^{23}$ The before-tax Gini coefficient for the United States is 38.5, whereas the average for European countries is 29.1 , which means that Europe appears to have significantly less before-tax inequality. The United Kingdom has the most income inequality in the European sample, but its Gini coefficient is still only 32.3. To examine skewness, we can look at the share of income earned by the top quintile. In the United States the top 20 percent of income earners take home 43.5 percent of the before-tax dollars. In Europe on average, the top quintile earns 37.1 percent of before-tax income, and in no European country does the top quintile earn more than 41 percent. It seems clear that the United States has more before-tax inequality than Europe and a more skewed income distribution. Although these numbers are before tax, redistribution may nonetheless have taken place in many ways before earnings occur at all (through education, for example). Indeed, lower before-tax income inequality may be yet another example of the effects of European redistribution. More generally, the evidence on whether inequality creates more redistribution is mixed at best. Roberto Perotti finds little support for this channel in a broad empirical investigation. ${ }^{24}$

There are two possible explanations for the apparent failure of beforetax inequality, as measured by the Gini coefficient, to lead to more redistribution. First, in countries with greater income inequality, the poor are unlikely to have much political clout and hence may not be able to extract much redistribution from the rich. That is, such countries may lack a oneperson, one-vote rule, which underlies the model's results, but instead have something closer to a one-dollar, one-vote rule. We devote much space below to a discussion of the political determinants of redistribution, and the political power of the poor is a critical factor. Second, the measured before-tax Gini coefficient is a poor indicator of before-tax inequality, because a host of other policies (in addition to the tax system) affect inequality, so that the Gini coefficient may overestimate the true before-tax inequality in the United States. However, the direct evidence on the minimum wage, discussed above, and on executive compensation suggests that this interpretation is not likely to hold.

23. See Deininger and Squire (1996).

24. Perotti (1996). Benabou (1996) also surveys the evidence and comes to a similar conclusion. 
THE COSTS OF REDISTRIBUTION. Proposition 2 also suggests that there might be more redistribution in Europe if taxation creates fewer distortions there, or if spending on redistribution in Europe is less likely to be associated with administrative costs or wasteful pet projects. For example, if Europeans have access to less distortionary forms of taxation, we would expect Europeans to have bigger welfare states.

Although we suspect that improvements in the technology of taxation have played a major role in increasing redistribution over time, we do not believe that European taxation is much more efficient than American taxation. ${ }^{25}$ Indeed, evidence on tax evasion suggests the contrary. Tax evasion does not itself capture inefficiency, but it does suggest limits to efficient tax collection. The ability of citizens to avoid taxes is a primary limit on the menu of forms of taxation that the state can use.

The 1996 Global Competitiveness Report surveyed business leaders about tax compliance in their countries. On this subjective measure the United States received a score of 4.47 (where 6 represents maximal compliance). Although there is considerable heterogeneity across Europe, on average tax compliance appears to be much lower there: the average score was 3.5. Furthermore, there is no evidence that Europeans impose less distortionary taxes. As discussed above, the tax structure in Europe is quite varied. Europe is the home of the value added tax, a consumption tax, which is thought to be less distortionary than a pure income tax. However, Europe also uses rent controls and certain labor market interventions that appear to be much more distortionary. ${ }^{26}$

Although redistribution in the United States is probably not more wasteful than redistribution in Europe, it certainly seems plausible that Americans are inherently more hostile to government, and more prone to believe that governments are wasteful and likely to spend on projects that the voters oppose. Indeed, the United States was created from an antigovernment revolution, and its history includes a civil war in which roughly half the country fought against the federal government. Fortyeight percent of European respondents to the World Values Survey favor

25. The strongest piece of evidence suggesting massive improvement in tax collection technology is the use of income taxes rather than much simpler taxes such as import fees and property taxes. It may well be true that differences in redistribution between the OECD and the developing world are a result of differences in access to less distortionary forms of taxation.

26. See, for example, Blanchard and Portugal (2001). 
greater government ownership in the economy, whereas only 26 percent of Americans express that opinion. This probably reflects a greater distrust of the state within the United States.

However, another piece of evidence makes it unlikely that American anti-statism alone explains the low level of redistribution in the United States and further casts doubt on the view that Europe has access to less distortionary taxes. If the real or perceived costs of government were higher in the United States, we would expect European governments to be bigger along every dimension, since, after all, they face a lower social cost of funds. As we discussed above, this is not the case.

SOCIAL MOBILITY AND INCOME UNCERTAINTY. The economic model presented above suggests that there are two ways in which social mobility can explain the gap between U.S. and European levels of welfare. First, the median voter in the United States might expect higher future income growth (relative to other Americans) than does the median voter in Europe. According to this theory, high income mobility in the United States (specifically, upward mobility of the median voter) can explain lower U.S. redistribution. Second, Europeans might demand more redistribution because they face more exogenous shocks to their incomes (perhaps because of the greater openness of their economies), and redistribution reduces risk. According to this theory, low income mobility in the United States could explain lower U.S. redistribution.

As we will discuss later, a third-behavioral-theory also links income mobility with redistribution. This theory suggests that, in societies with high income mobility, the nonpoor are more likely to believe that poverty is due to laziness. In more static societies, where birth determines income, the nonpoor are more likely to think that the disadvantaged are poor solely because of the accident of their birth. We will discuss this theory in the section on the determinants of altruism, and for now note simply that this theory offers an alternative interpretation of why higher American mobility might be associated with less redistribution.

Alesina and Eliana La Ferrara provide evidence on the first economic theory linking economic mobility with support for redistribution. ${ }^{27}$ They find that individuals with greater expected income growth are more likely to oppose redistribution. Using U.S. data, these authors compute the probability that individuals in different income brackets will reach levels of

27. Alesina and La Ferrara (2001). 
income in the future that will make them net losers from redistribution. This probability of upward mobility is a strong predictor of individual support for redistribution.

For this theory to explain differences in redistribution between the United States and Europe, it must be the case that the median voter in the United States is more likely than the median European voter to become rich at some future date. This probability combines higher mobility with the specific chance of moving upward for individuals in the middle of the income distribution. There are two types of evidence on this question: actual income mobility data and survey questions about income mobility. Survey questions seem to have the advantage of getting directly at individual beliefs, which should be the direct determinant of voting behavior. Differences in income mobility across countries turn out to be quite controversial, ${ }^{28}$ and measurement here is difficult because of the high degree of idiosyncratic measurement error present in all survey measures of individual income.

It is clear that Americans believe they live in a country with greater income mobility. According to the World Values Survey, 71 percent of Americans, but only 40 percent of Europeans, believe that the poor have a chance to escape from poverty. But although these survey questions suggest very different beliefs about mobility, they do not directly relate to the relative income growth prospects of the median voter. Indeed, the question seems to relate more to feelings about the poor and the altruistic sources of redistribution than to the financial gains from redistribution to the median voter.

Harder data on income mobility do not suggest such strong differences in mobility for the middle classes between the United States and Europe. For example, Peter Gottschalk and Enrico Spolaore construct a fifteenyear transition matrix by income quintile for the United States and Europe.$^{29}$ This matrix shows the shares of the middle income quintile in 1984 who were in various income quintiles in 1999. The similarity observed between the United States and Germany is striking, even though there seems to be a slightly higher upward mobility of the middle class in the United States. Ten percent of Germans, and 11 percent of Americans, in the middle quintile moved to the top quintile over the period. Twenty-

28. Fields and Ok (1999) provide a survey.

29. Gottschalk and Spolaore (2001). 
one percent of Germans, and 23 percent of Americans, in the middle quintile moved up to the second quintile. An almost identical share (31 percent) of both groups stayed in the middle quintile. Middle-quintile Germans were somewhat more likely to end up in the bottom quintile (16 percent versus 12 percent of Americans) and were correspondingly less likely to end up in the next lowest quintile, but overall the differences seem small. Daniele Checchi, Andrea Ichino, and Andrea Rustichini suggest that mobility is higher in the United States than in Italy. ${ }^{30}$

The survey by Gary Fields and Ok suggests a wide range of estimates on income mobility and the comparison between the United States and Europe. However, there is no clear-cut evidence that the middle quintile in the United States has substantially more upward relative mobility than its German counterpart. The bottom line of the evidence presented by Alesina and La Ferrara is that upward mobility is important. Americans believe that there is more upward mobility in their country. These two facts together can explain an aversion to redistribution. The question of whether this perception of greater mobility in the United States is correct or mistaken awaits further research.

The second theory - that income variability drives demand for redistribution - has received less extensive testing. An exception is work by Dani Rodrik, which focuses on the variability of income induced by openness, an argument to which we now turn.

Rodrik, following a suggestion by David Cameron, has argued that the size of government and, especially, of income support policies is explained by the openness of the economy. ${ }^{31}$ Figure 2 highlights this relationship. According to Rodrik, open economies are more "unstable" because they are more subject to external shocks. Larger public transfers provide insurance and reduce instability in the stream of lifetime income of individuals. Thus, more open economies "need" a larger government. Alesina and Romain Wacziarg argue that open economies are small, that is, that size and openness are strongly inversely correlated..$^{32}$ Because small economies tend to be more open, it is difficult to disentangle the openness argument from an alternative one, namely, that in larger economies the size of government per capita, or as a share of GDP, is smaller because of economies

30. Checchi, Ichino, and Rustichini (1999),

31. Rodrik (1998); Cameron (1978).

32. Alesina and Wacziarg (1998). 
Figure 2. Relationship between Transfers and Openness in OECD Countries

Transfers (percent of GDP)

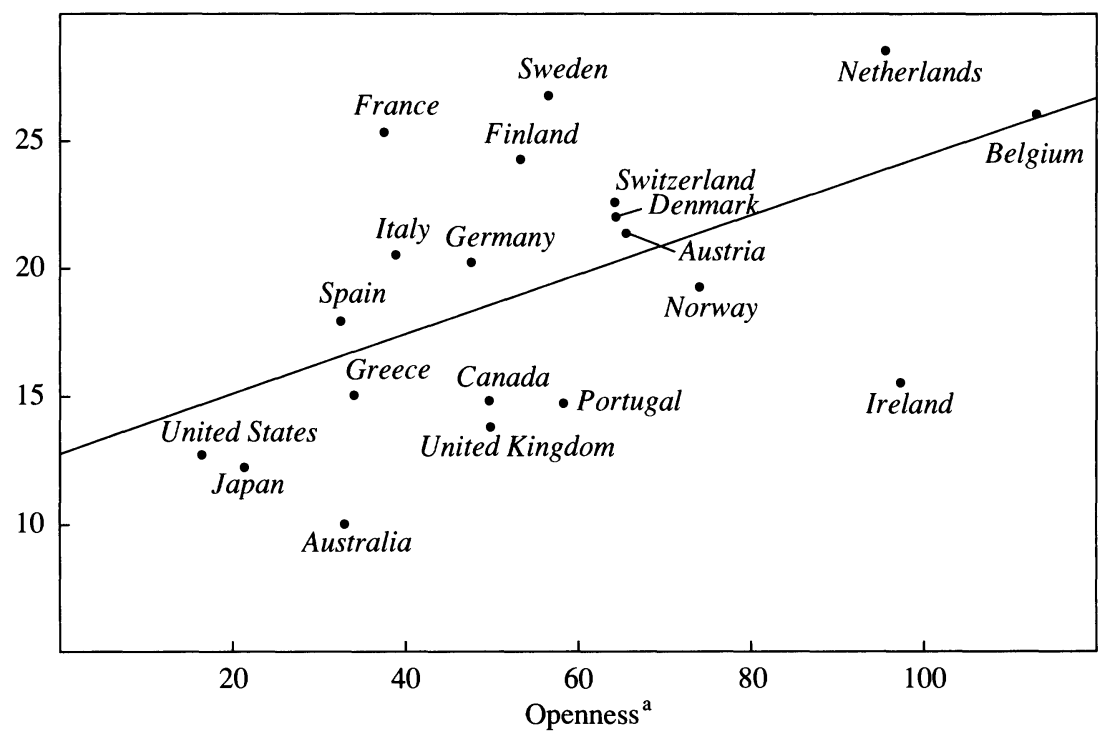

Source: Authors' calculations based on data for 1960-98 from the IMF and Persson and Tabellini (2000).

a. Sum of exports and imports, as a share of GDP.

of scale in the production of public goods. ${ }^{33}$ However, the openness argument should apply more directly to transfer programs, and the economiesof-scale idea more to public goods and infrastructure. Since in the present paper we are concerned with transfers and welfare programs, the openness argument is, in principle, especially appealing.

The United States is a larger and less open economy than any in Europe, but as table 7 shows, it is also less stable than the average European economy. In terms of growth, unemployment, and productivity, the U.S. economy has displayed more volatility than the average of the European countries over the last forty years. The table also reports Rodrik's measure of externally induced volatility, which multiplies an economy's termsof-trade volatility by its degree of openness (measured as exports plus imports, divided by GDP). This can be interpreted in two ways. First, the U.S. economy may have more variability precisely because transfers are smaller. However, since the U.S. economy is more closed, it should be less

33. See Alesina and Spolaore (1997) for further discussion. 
Table 7. Standard Deviations of Selected Economic Indicators in the United States and the European Union, 1960-2000

\begin{tabular}{llcc}
\hline Series & Period & United States & European Union \\
\hline GDP growth & $1960-97$ & 0.020 & 0.017 \\
Labor productivity in manufacturing & $1980-96$ & 0.026 & 0.016 \\
Unemployment rate $^{\mathrm{a}}$ & $1970-2000$ & 0.414 & 0.220 \\
Competitiveness $^{\mathrm{b}}$ & $1975-99$ & 0.057 & 0.046 \\
Terms of trade $^{\mathrm{c}}$ & $1971-90$ & 0.086 & 0.088 \\
Externally induced volatility $^{\mathrm{d}}$ & $1971-90$ & 1.650 & 7.010 \\
\hline
\end{tabular}

Source: Authors' calculations based on data from OECD, OECD Statistical Compendium, 1999; and Rodrik (1998).

a. Standard deviation divided by the mean.

b. Index of relative export price of manufactured goods. EU average is for France, Germany, Italy, Spain, and the United Kingdom.

c. From Rodrik (1998). This measure reports the standard deviation of the differences in terms of trade (expressed as logarithms)

d. Terms-of-trade volatility times the sum of exports and imports as a share of GDP.

in need of a larger government. In other words, if all countries shared the same objectives in terms of the trade-off between government size and business cycle variability, the United States should be more, not less, stable than Europe. ${ }^{34}$ Since it is larger and more closed to begin with, it should cost less in terms of taxation to achieve the same level of stabilization. ${ }^{35}$ Therefore, if Rodrik's theory is correct, the fact that the United States has experienced greater variability than Europe suggests that Americans and Europeans evaluate very differently the trade-off between government size and cyclical variability. Whether or not openness is a major determinant of the size of government remains, in any case, an unsettled issue.

\section{Political Explanations}

Our examination of the possible political explanations of U.S.-Europe differences begins with several cross-country regressions relating selected features of countries' electoral systems to the extent of redistribution; we then discuss the role of political history.

34. Similar considerations apply to Japan, a country that has a small government, is relatively closed (and large), and exhibits more income variability than the European countries.

35. An additional measure of income uncertainty could be the extent of long-term unemployment. However, this measure is very likely to be directly affected by labor market regulation and policies. 
CROSS-COUNTRY REGRESSIONS: THE ELECTORAL SYSTEM. A lively recent literature has investigated theoretically and empirically the relationship between electoral rules and fiscal policy. ${ }^{36}$ Particularly relevant for our purposes is recent work by Gian Milesi-Ferretti, Perotti, and Massimo Rostagno (MFPR) and by Torsten Persson and Guido Tabellini (PT) ${ }^{37}$ These papers test the hypothesis that, in majoritarian systems characterized by geographically based districts in which each district chooses one representative, the elected government will favor spending programs that can be geographically targeted. Proportional electoral systems, in contrast, will favor spending on universal programs, according to this hypothesis, since in each district more than one representative is elected in proportion to the vote received. The clearest example of this is a purely proportional election in a single national district. In this case geographic targeting would make no sense at all.

To test these ideas, one needs to measure the degree of proportionality of electoral systems and to differentiate between spending programs that can be geographically targeted and those that cannot. In theory the contrast between these two types of programs is clear-cut; in practice, less so. For instance, anyone above a certain age is eligible to receive social security payments, regardless of residence. However, certain districts may be disproportionately populated by elderly voters. In any event, the hypothesis tested is that universal transfer programs should be larger in countries with more proportional electoral systems.

Both MFPR and PT report results consistent with this hypothesis. The two papers use different measures of transfers, a different sample of countries (that of PT is larger), and a different definition of proportionality. Appendix B explains these differences in the data sets more precisely, but one important observation concerning the dependent variable is that MFPR use OECD data as a source for OECD countries and a data set constructed by Michael Gavin and Perotti for Latin America. ${ }^{38}$ All these data refer to the general government. PT, in contrast, use International Monetary Fund data, which are focused on the central government. This distinction is especially important if one is comparing the United States with other countries: the United States is a federal system in which the differ-

36. Persson and Tabellini (2000) provide an exhaustive review of this area of research.

37. Milesi-Ferretti, Perotti, and Rostagno (forthcoming); Persson and Tabellini (2000). See also Persson (2001).

38. Gavin and Perotti (1997). 
ence between central and general government data is much larger than in most other countries. To measure proportionality, PT use a variable, obtained from "Interparliamentary Union," that assumes the value of one if a country has a majoritarian system and zero otherwise. Obviously, electoral systems differ on many dimensions, and a zero-one dummy may miss important differences between the two groups of systems lumped together.

For this reason, MFPR construct (for a smaller sample of countries) a continuous variable based on the following idea. They want to capture the share of electoral votes that guarantees a party a parliamentary seat in an electoral district of average size. This variable, labeled $U M S$ (for "upper marginal share"), is declining in proportionality, since the higher is $U M S$, the more difficult it is for small parties to gain access to parliament. In a two-party system with a first-past-the-post rule, $U M S$ takes a value of 0.5 . This value declines with the degree of proportionality of the system. As these authors show, constructing this variable is not a simple task, because of the many dimensions on which electoral systems differ across

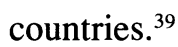

Table 8 presents results we obtained using the data sets kindly provided by the authors of these two papers. Column 8-1 reports the MFPR regression on OECD countries. The proportionality variable is constructed as an "average district size," and it is a one-to-one inverse transformation of $U M S .{ }^{40}$ Thus one should expect a positive sign on this variable if transfers are larger in more proportional systems. And in fact this variable (in logarithms) has a highly significant positive coefficient. The other controls used by MFPR are insignificant.

39. There is an additional channel through which the electoral system may influence fiscal policy, namely, the degree of fragmentation of the legislature. Since in proportional systems it is easier for small parties to gain representation, proportionality leads to multiparty coalition governments and a fragmented policy arena. Theoretical work by Alesina and Drazen (1991) and Tornell and Velasco (1995), among others, shows how fragmentation of the political system leads to larger and more persistent deficits. Empirical work by Roubini and Sachs (1989a, 1989b) and Kontopoulos and Perotti (1999), among others, provides support for this hypothesis with regard to OECD countries. In these papers, fragmentation is measured as a function of the number of parties represented in the government coalition or in the legislature, or by the number of different ministers in the government with authority over spending. Interestingly, Milesi-Ferretti, Perotti, and Rostagno (forthcoming) show that the degree of proportionality of the electoral system affects transfers even when measures of fragmentation are controlled for.

40. The transformed variable is called the standard magnitude $(S M)$, where $S M=$ $1 /(1-U M S)$. 
Table 8. Cross-Country Regressions Explaining Transfers with Political Variables ${ }^{\mathbf{a}}$

\begin{tabular}{lcccc}
\hline Independent variable & $8-1$ & $8-2$ & $8-3$ & $8-4$ \\
\hline Proportionality $^{\mathrm{b}}$ & $2.150^{* *}$ & $1.809^{*}$ & $1.021^{*}$ & \\
& $(0.656)$ & $(0.728)$ & $(0.421)$ & \\
GDP per capita & 5.151 & 5.035 & 1.823 & -0.876 \\
& $(3.571)$ & $(3.558)$ & $(1.519)$ & $(0.980)$ \\
Openness $^{\mathrm{c}}$ & & 0.043 & 0.032 & 0.009 \\
& & $(0.040)$ & $(0.027)$ & $(0.010)$ \\
Percent of population over 65 & 0.753 & 0.678 & $1.096^{* *}$ & $1.315^{* *}$ \\
Percent of population aged 15-64 & $(0.478)$ & $(0.481)$ & $(0.298)$ & $(0.217)$ \\
& & & & 0.140 \\
Majoritarian regime dummy & & & & $(0.138)$ \\
& & & & -1.526 \\
Presidential regime dummy & & & & $-0.994)$ \\
& & & & $(1.227)$ \\
Asia dummy & & & & 2.047 \\
Caribbean dummy & & & & -0.095 \\
& & & -0.791 & $(2.164)$ \\
Latin America dummy & & & & 1.042 \\
& & & & \\
Summary statistic & 20 & 20 & 38 & $6.102)$ \\
No. of observations & 0.58 & 0.61 & 0.84 & 0.82 \\
$R^{2}$ & & & & \\
\hline
\end{tabular}

Source: Authors' calculations using data from Milesi-Ferretti, Perotti, and Rostagno (forthcoming); Persson and Tabellini (2000); and Perotti (1996).

a. Regressions 8-1 through 8-3 use transfers as a share of GDP as the dependent variable and data for 1991-94 from MilesiFerretti, Perotti, and Rostagno (forthcoming). Regression 8-4 uses social spending as a share of GDP as the dependent variable and data for 1960-98 from Persson and Tabellini (2000). All specifications include a constant (not reported). $t$ statistics are reported in parentheses. ${ }^{*}$ denotes significance at the 5 percent level, ${ }^{* *}$ at the 1 percent level.

b. Measure of the percentage of a district's vote needed to capture a seat, expressed in natural logarithms. From Perotti (1996).

c. Exports plus imports as a share of GDP.

d. Equals one in a regime where all seats in a district are awarded to the party that wins the district.

The regression in column 8-2 adds a measure of openness (exports plus imports, divided by GDP). This variable turns out to be insignificant. Following MFPR, we also explored Rodrik's specification of openness, which includes a variable representing the interaction of terms-of-trade shocks with openness, but we did not find a significant relationship (results not shown; MFPR report the same result). Column 8-3 reports the MFPR result using the entire sample, including Latin America. The proportionality variable is still significant, but the size of the coefficient is much lower and less precisely estimated. (Note that openness is still insignificant.) Figure 3, which plots transfers as a share of GDP against the measure of proportionality for the OECD countries (top panel) and for the 
Figure 3. Relationship between Transfers and the Degree of Proportional Representation

\section{OECD countries}

Transfers (percent of GDP)

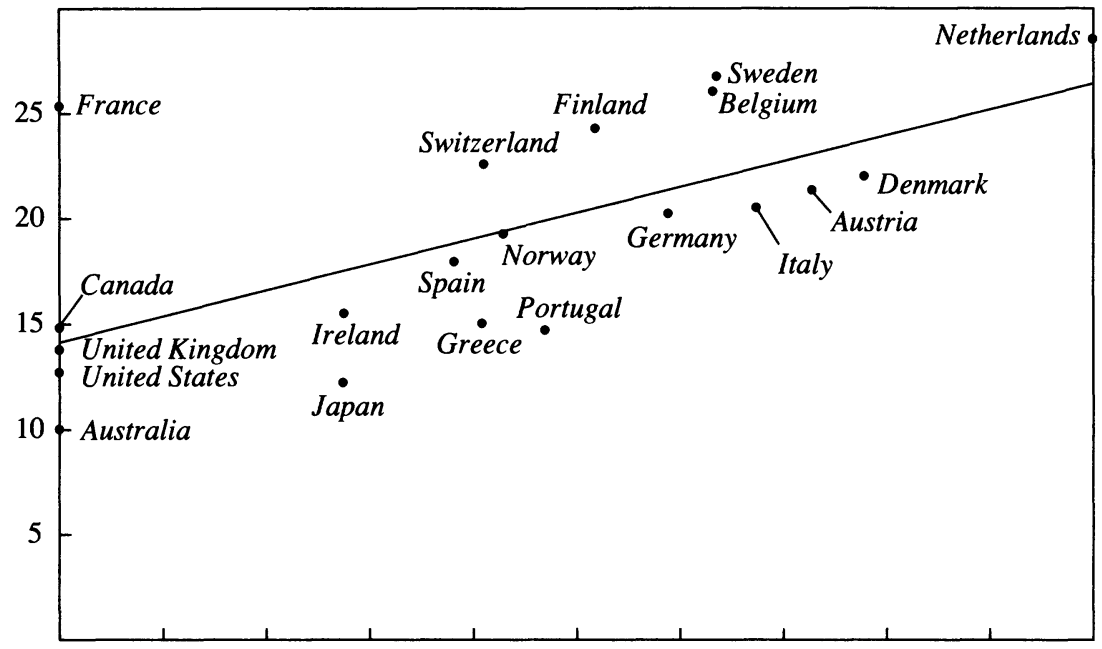

Latin American countries

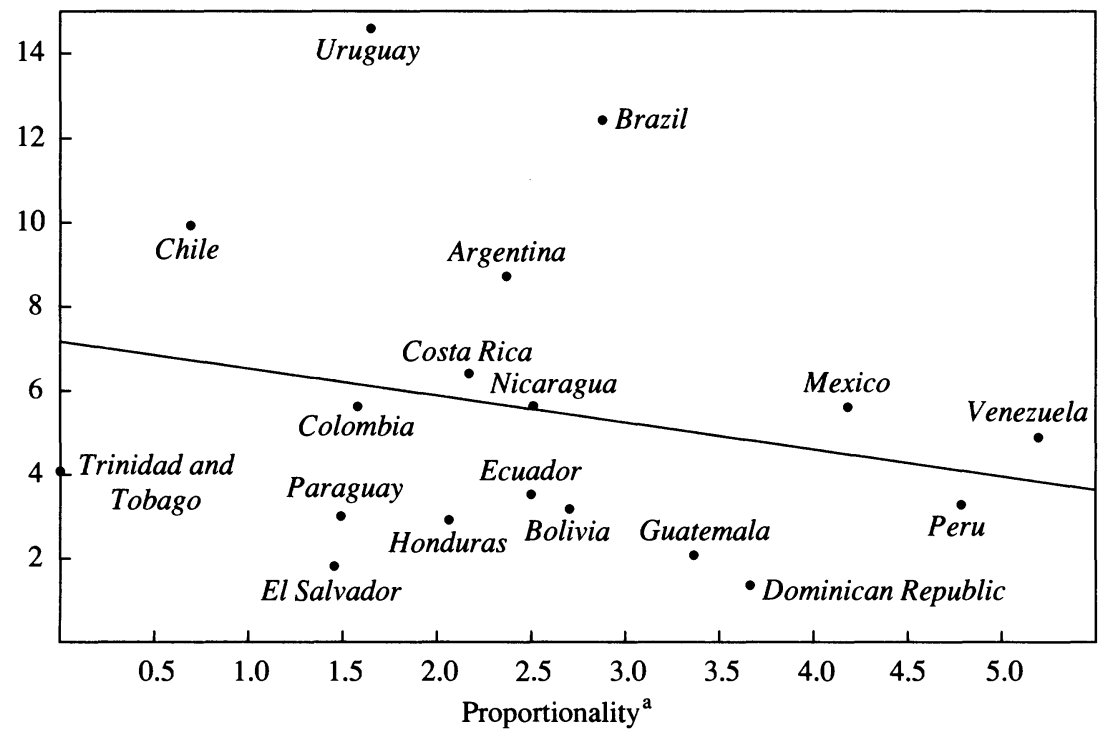

Source: Data for 1991-94 from the OECD; Milesi-Ferretti, Perotti, and Rostagno (forthcoming); and Perotti (1996).

a. Measure of the percentage of a district's vo.e needed to capture a seat, expressed in natural logarithms. From Perotti (1996). 
Latin American countries (bottom panel), shows why: the correlation for the OECD countries is very strong and positive whereas that for the Latin American countries is very weak and negative.

Column 8-4 in table 8 uses the PT data set, which allows us to expand the set of countries. We use their specification. In particular, in addition to the majoritarian variable, PT focus on another political variable, namely, whether or not a country has a presidential regime. Note that one should expect a negative sign on both the presidential and the majoritarian variable. Neither, however, is significant in this large sample (nor is the openness variable). If we restrict the sample to the OECD countries, the two political variables come much closer to significance (results not shown), but the MFPR measure of proportionality seems to be more strongly correlated with the dependent variable than do the PT variables. Openness is insignificant in the OECD subsample as well.

The bottom line seems to be that, for OECD countries, a measure of proportionality of the electoral system is highly correlated with the amount of government transfers. This correlation is much weaker or nonexistent for developing countries. The openness variable is not significant after one controls for political variables.

If we interpret the coefficient on proportional representation as reflecting a causal relationship, the cross-country regressions just described suggest that if the United States had an electoral system similar to that of, say, Sweden, the welfare states in the two countries would be very similar. This narrow interpretation of political explanations is incomplete, however. The electoral system is only one of the politico-institutional forces that have led the United States to diverge from Europe. In addition, the electoral system may itself be endogenous to other variables, including attitudes toward the poor, which we discuss later.

One may argue that, in the United States, the present electoral system was chosen and maintained precisely because it supported certain policy outcomes. Post-World War II France went back and forth from more to less proportionality, in part to suit the needs of its various leaders. ${ }^{41}$ Italy recently moved to a less proportional rule in response to the perceived failures (including in fiscal matters) of the previous proportional system. New

41. In 1958 President Charles de Gaulle changed the proportional system of the Fourth Republic, making it more majoritarian. President François Mitterrand reintroduced proportionality in 1986 . 
Zealand recently made a move in the opposite direction. Nevertheless, electoral laws have a certain "stickiness" and do not change often. Our preferred interpretation is that although electoral systems in part reflect deeper aspects of the societies that create them, they also have an important direct effect on redistribution.

THE IMPACT OF POLITICAL HISTORY. No discussion of political variables would be complete without taking a historical perspective. Three monumental historical forces distinguish the United States from Europe: the Civil War, the "open frontier" in the American West, and the absence of a large and influential socialist or communist party.

Skocpol notes that, at the end of the nineteenth century, the United States had a minimal welfare state similar to that of the European countries at the time. ${ }^{42}$ The welfare system that did exist was based on veterans' pensions that grew more and more generous over time and had more and more relaxed eligibility requirements. Several social reformers viewed this program as the steppingstone toward a universal social security system. However, their efforts were halted by several factors. One of these was a general mistrust in the administration of the veterans program, and another the fact that it emerged from the divisive experience of the Civil War, rather than from a cohesive one such as an external war. Yet another was that the U.S. courts during this period systematically rejected any legislation that was perceived as anti-business. In doing so, they appealed to the principle of protection of private property against government intervention; often the doctrine of freedom of contract was invoked. Most strikingly, in 1895 the courts declared the U.S. income tax to be unconstitutional, and it took a constitutional amendment to undo this decision. ${ }^{43}$ The pro-property actions of the courts were influenced both by the U.S. Constitution, which was designed by property owners in part to protect property from democracy's excesses, and by incentives that firms created to influence judges.

Different legal systems (for example, the French versus the AngloSaxon system) attribute very different roles to the courts, whose institutional structure also differs across countries. ${ }^{44}$ The involvement of the

42. Skocpol (1992).

43. The Supreme Court's decision in this case was far from a foregone conclusion. The United States had had a functioning income tax during the Civil War, which the court did not challenge.

44. See Glaeser and Shleifer (2001a) for a recent discussion. 
courts in social legislation in the United States has been a constant feature of the U.S. experience, unlike that in countries whose legal tradition is based on the French or the German model. Indeed, the power and independence of the U.S. courts are unique, unmatched even in England, where parliamentary dominance is much more established. In the United Kingdom, the House of Lords was the closest equivalent to the U.S. Supreme Court until its power was stripped from it in the triumph of parliamentary democracy.

Given the relative failure of public provision of welfare in the United States at the end of the nineteenth century, social assistance took a turn toward private initiatives, which permeate U.S. society even today. ${ }^{45}$ Skocpol, Ganz, and Munson document the active role of a varied universe of civic associations that provide many different forms of assistance to their members and target groups. ${ }^{46}$ Many of these organizations have national coverage. Obviously, these private organizations fall well short of providing the kind of social protection that a European government would offer. However, this is another example of the fact, documented above, that private charities in the United States tend to substitute somewhat for the lower provision of public assistance.

The open frontier in a country of immigrants strengthened individualistic feelings and beliefs in equality of opportunities rather than equality of outcomes. In fact, one may argue that self-selection led to a systematic difference between those Europeans who migrated to the United States and those who did not. The former might have been those that, ceteris paribus, were more responsive to individual incentives and less risk averse. This, of course, contributed to cementing an anti-statist feeling that still pervades American culture.

A related factor is the lower population density of the United States. Redistribution in many countries has been a response to the physical power of the poor and the threat of riot and revolution. Daron Acemoglu and James Robinson argue that democracy in Europe is itself a response to this power. ${ }^{47}$ Although America saw its share of class-related violence in the

45. A particularly interesting example at the end of the nineteenth century was the role of women's organizations in providing family assistance to mothers and children (Skocpol, 1992).

46. Skocpol, Ganz, and Munson (2000).

47. Acemoglu and Robinson (2000). 
late nineteenth century, ${ }^{48}$ and experienced riots in the 1930 s and the 1960 s, its geographic decentralization has generally meant that the United States has never witnessed a rebellion that threatened the centers of government. ${ }^{49}$ In contrast, popular uprisings in Paris led to changes of government on at least four occasions. Berlin and London were more stable but still faced considerably more popular unrest than Washington, D.C.

Indeed, across OECD countries population density is found to have a significant positive effect on redistribution: 38.6 percent. Elsewhere one of us has argued that urban density facilitates riots and rebellions. ${ }^{50}$ More generally, the historical evidence from countries like France suggests that urban density leads to the political empowerment of the poor, certainly relative to the dispersed farmers of the eighteenth century. Hence America's low population density may also have contributed to its stability and relative lack of redistribution..$^{51}$

The absence of a large and cohesive socialist workers' movement in the United States is another critical factor in shaping redistributive policies. Marx and Engels (especially the latter) were already aware of what we now call "American exceptionalism." They attributed it to the lack of a feudal period in American history: because it missed this phase, American society failed to create the basis of clear-cut class differences. ${ }^{52}$ Already in the nineteenth century, the workers' movements that could have become the precursors of a socialist party professed an "ideology that reflected the strong belief of many Jacksonian Americans in equality of opportunity, rather than equality of results.. ${ }^{53}$ In fact, workers' groups in the United States were "social Darwinist, not Marxist." ${ }^{44}$ Werner Sombart, himself then a socialist, argued that American capitalism may create inequality but offered opportunities to all. He wrote that "Equality and Liberty ... [for American workers] are not empty ideas and vague dreams

48. See Skowronek (1982).

49. The Civil War was, of course, fundamentally a rebellion of the Southern elites, who can be interpreted as fighting for the right to take from the poor without compensation.

50. DiPasquale and Glaeser (1998).

51. It is also possible that density has a second effect on redistribution, working through altruism. If proximity creates empathy, one might expect support for welfare to be stronger in denser countries.

52. For an extensive review of the writings of Marx and Engels concerning the American case see Lipset and Marks (2000).

53. Lipset and Marks (2000, p. 21).

54. Lipset and Marks (2000, F. 20). 
as they are for the European working class." ${ }^{55}$ In other words, class struggle was (and is) not "second nature" to the American workers. In Sombart's words, "In America there is not the stigma of being the class apart that almost all European workers have about them." 56

The fact that the American working class was formed by waves of immigration also contributed to preventing the formation of a Europeanstyle class consciousness. Ethnic divisions within the working class (early Protestant immigrants on one side, new Catholic immigrants on the other) were as strongly felt as class-based cleavages. ${ }^{57}$ Even contemporary socialist leaders (including Engels) recognized the powerful effect of ethnic fragmentation within the union movement.

The Great Depression could have galvanized socialist ideals in the United States. However, with the New Deal, President Franklin Roosevelt and the Democratic Party managed to co-opt important fringes of the left, which might otherwise have strengthened the Socialist Party. At the same time, the Socialists persisted in not understanding and in not accommodating "distinctive elements of American culture-antistatism and individualism." ${ }^{58}$ These cultural features were of course at odds with the socialist emphasis on taxation and heavy government intervention. American socialists were systematically less successful than their counterparts in other Anglo-Saxon countries, such as Australia, Canada, and the United Kingdom itself, in working with these cultural characteristics. Finally, one should not forget the role of repression of communism and socialism in post-World War II America.

The electoral system also made it difficult for a third party to move into the political arena, as emphasized, for instance, by Lipset. ${ }^{59}$ This observation is consistent with the econometric evidence described above on the importance of proportional representation. However, the interpretation is different from those of the models sketched above. The U.S. electoral rules, by making it difficult for third parties to enter, contributed to the failure of socialist and communist parties in the United States.

Additionally, the United States evolved as a federal system rather than as a unitary, centralized country like several of today's European countries.

55. Sombert (1905, p. 75).

56. Sombert (1905, p. 76).

57. See Lipset and Marks (2000) and the vast literature cited therein on this point.

58. Lipset and Marks (2000, p. 266).

59. Lipset (1996). 
To the extent that the redistributive role of the central government is in part delegated to subnational levels of government, the geographic mobility of individuals and tax competition between subnational governments might limit government size. ${ }^{60}$ Even though the cross-country evidence on the relationship between fiscal decentralization and the size of government is inconclusive (after all, Germany, too, is a federal republic), ${ }^{61}$ the fact that many public goods in the United States are locally provided may affect the extent of redistribution to the poor. Think, for instance, of people fleeing to the suburbs to escape the taxation needed to finance inner-city schools. However, the choices concerning these fiscal arrangements and the relationship between different levels of governments are clearly endogenous to preferences for redistribution.

As a final aside, it is worth reemphasizing that all political rules are in some sense endogenous and the outcome of deeper features of the country in question. The writers of the U.S. Constitution chose to establish a federal system with strong separation of powers, a bill of rights, and proportional representation. It is very clear that the Founding Fathers, James Madison in particular, were focused on protecting American citizens against the "encroaching spirit of power" and "the violence of faction."62 The authors of the Constitution make it clear in the Federalist Papers that they are disturbed by the possibility that, in an unfettered democracy, "measures are too often decided, not according to the rules of justice and the rights of the minor party, but by the superior force of an interested and over-bearing majority." ${ }^{3}$ They therefore tried to design the Constitution so as to protect private rights against factions, even if those factions include a majority of the population.

Of course, the United States is not the only country with a constitution designed to limit the majority's power by protecting property. In the premodern era, electoral rules designed by elites customarily attempted to protect property against majoritarian redistribution. However, the big difference between the United States and most of Europe is the former's greater political stability, which means that eighteenth-century rules are still in effect today. Whereas many European monarchies were toppled by

60. For a recent survey of the literature on this point see Oates (1999).

61. In fact, in many cases decentralization has led to an increase in spending, and it is often a source of fiscal imbalance.

62. The Federalist, No. 10.

63. The Federalist, No. 10. 
world wars and revolutions, the United States has had an enormously stable system of government. Indeed, across countries we see a significant relationship between the date of the most recent constitution and the extent of redistribution. In a sample of sixteen OECD countries, the correlation between social spending and the year of the most recent constitution is 52 percent. ${ }^{64}$ Indeed, America's stability may be one of the true causes of its electoral rules that seem to limit redistribution.

Political factors that influence U.S. exceptionalism run deeper than differences in electoral rules. It is highly unlikely that, holding the rest of history constant (including the endurance of the U.S. Constitution, the Civil War, the waves of immigration, ethnic fragmentation, and the difficulty of establishing a unified socialist working class movement), a change in the electoral rules for Congress would have turned the U.S. welfare state into one resembling that of France or Sweden. In addition, Americans may not have wanted a change in their electoral rules, precisely because they feared the consequences of such a change on policy outcomes.

\section{Behavioral Explanations}

The previous section explored reasons why political institutions could explain different levels of redistribution in the United States and Europe, even if the demand for redistribution were the same in both places. Now we look at theories of why the demand for redistribution might differ between Europe and the United States, and in particular why the median voter in Europe might be more positively disposed toward the poor than the median voter in the United States.

The economic literature on the determinants of altruism is limited. We know of two main strands. First, a substantial body of work, following Gary Becker, argues that people like people of their own race more than they like people of other races. ${ }^{65}$ Second, a smaller and more recent body of work explores the concept of reciprocal altruism: that people feel altruistic toward those who are good to them and vengeful toward those who

64. The sample excludes both the Netherlands and Belgium. Although their constitutions date from 1814 and 1830 , respectively, change in these countries has been quite dramatic, as they have moved away from monarchism toward republicanism over the past 200 years. If we include these countries and weight the sample by population, the correlation is 58 percent. However, the correlation is only 9.5 percent if we include Belgium and the Netherlands and do not use population weights.

65. Becker (1957). 
take advantage of them. In the welfare context, reciprocal altruism means that people will vehemently oppose welfare if they believe that welfare recipients are taking advantage of the system.

RACIAL PREJUDICE. Becker's model, which assumes that people of one race dislike people of another race, launched the modern economic literature on racial discrimination. There is, of course, a vast literature on different aspects of discrimination. Gordon Allport's classic sociology text describes the early work in this area that shows discrimination in a wide array of settings. ${ }^{66}$ More recent work has shown the impact of racial discrimination on markets ranging from baseball cards to housing. ${ }^{67}$ Alesina and La Ferrara show that participation in social activities involving direct contact between individuals is lower in racially fragmented communities in the United States. ${ }^{68}$ The same authors show that trust is higher in more racially homogeneous communities. ${ }^{69}$ Work by Glaeser and others documents experimentally that people of different races are more likely to cheat one another. ${ }^{70}$

Racial heterogeneity seems to be a significant factor in the political process. Alesina, Reza Baqir, and Caroline Hoxby show that individuals prefer to form racially homogeneous political jurisdictions. ${ }^{71}$ Denise DiPasquale and Glaeser document that racial heterogeneity is closely linked to the incidence of riots. ${ }^{72}$ Other forms of heterogeneity (in national origin and religion) appear to be much less important. In other parts of the world, religious cleavages (for instance) may be much more deeply felt than racial ones, but in the United States the most salient dividing line is race.

We do not really know why interpersonal altruism seems linked to race. It is possible that human beings are hard-wired to dislike people with different skin color. A more reasonable theory is that human beings are genetically programmed to form in-group, out-group associations and to prefer members of what they perceive as their own group. An extensive social

66. Allport (1954).

67. On discrimination in baseball cards, see Nardinelli and Simon (1990). Taeuber and Taeuber (1965) is the classic text on housing market segregation, and Cutler, Glaeser, and Vigdor (1999) trace its evolution.

68. Alesina and La Ferrara (2000).

69. Alesina and La Ferrara (2001).

70. Glaeser and others (2000).

71. Alesina, Baqir, and Hoxby (2000).

72. DiPasquale and Glaeser (1998). 
psychology literature documents individuals' tendencies to favor members of their own group; it also reveals the malleability of group definitions. A particularly famous experiment randomly allotted boys into different teams and then documented how these boys became deeply hostile toward members of rival teams. According to this view, race may serve as a marker for in-group status, but it need not be such a marker.

Other markers are available for group identification, but, again, in the United States race seems to be the strongest. In fact, political entrepreneurs in the United States often try to use race as an excuse for expropriation. For example, Dinesh D'Souza argues that modern racism came about as a justification for the profitable slave trade. ${ }^{73}$ During the post-Civil War reconstruction, Southern political leaders pushed a racist philosophy as an excuse for taking on the basis of race (and not income). We do not know why altruism seems to be lower between races than within them, but certainly a vast amount of evidence suggests that racial prejudice is a real and enduring feature of the American landscape.

The history of American welfare suggests that enemies of welfare often used race to defeat attempts at redistribution in the post-Civil War period. For example, during the populist era in the late nineteenth century, the United States first contemplated significant government action to redistribute income toward poorer Americans (specifically farmers) other than Civil War veterans. In the South, political action against such populist proposals frequently took the form of racial politics. C. Vann Woodward describes how conservative Democrats in the South used racial politics to defeat the left-wing Readjuster movement. ${ }^{74}$ The poll tax and literacy tests, which reduced voting by the poor of both races in the South, were enacted because they disproportionately disenfranchised African-Americans. A later example of how racial animosity was used to defeat left-leaning politics is George Wallace - the famous proponent of race-based policies in Alabama-who originally ran for governor in 1958 on a primarily antirich ticket. He was defeated, in that first run, by a more racist candidate who was endorsed by the Ku Klux Klan. More recently, national campaigns of relatively anti-welfare candidates have often attempted to play

73. D'Souza (1995). In particular, he claims that the Enlightenment had made slavery of one's peers unacceptable, making it necessary to define blacks as an out-group that could "ethically" be enslaved.

74. Woodward (1955). 
the race card (some observers have alleged the same about the presidential campaigns of both Ronald Reagan and the elder George Bush).

A natural generalization of race-based theory is that Americans think of the poor as members of some different group than themselves, whereas Europeans think of the poor as members of their own group. Racial differences between the poor and the nonpoor in the United States will tend to create the perception of the poor as "other," but geographic or social isolation might do this as well. If the poor in the United States are geographically or socially isolated, this might create a situation where nonpoor Americans have little sympathy for the poor. Furthermore, as Lipset has noted ${ }^{75}$ several polls suggest that a large majority of white Americans believe that African-Americans would be as wealthy as whites if they tried hard enough.

Hard evidence on the importance of race and in-group status in the support for welfare corroborates these anecdotes. Erzo Luttmer, using data from the General Social Survey in the United States, finds that support for welfare is greater among people who live close to many welfare recipients who are of the same race. ${ }^{76}$ This supports the idea that geographic isolation from the poor may lead Americans to think of them as members of some out-group.

Conversely, support for welfare is lower among people who live near welfare recipients of a different race. The difference between within-race and across-race effects seems to mean that people have a negative, hostile reaction when they see welfare recipients of a different race, and a sympathetic reaction when they see welfare recipients of their own race. Alesina, Baqir, and William Easterly use data on U.S. cities, metropolitan areas, and counties to look at the effect of race on redistribution. ${ }^{77}$ They find that states that are more ethnically fragmented spend a smaller fraction of their budget on social services and productive public goods, and more on crime prevention and (probably) on patronage.

This racial argument provides us with our first reason why tastes for redistribution might be lower in the United States. ${ }^{78}$ The United States is much more racially heterogeneous than Europe, and importantly,

75. Lipset (1996, p. 133).

76. Luttmer (2001).

77. Alesina, Baqir, and Easterly (1999).

78. This view is shared by Lipset (1996), among others. 
American minorities are disproportionately represented among the poor. It could be argued that ethnolinguistic heterogeneity within some European countries (such as Belgium) is as great as racial heterogeneity in the United States. Furthermore, it is at least possible that this heterogeneity creates antipathy that is as robust as the race-based animosity observed in the United States. However, in no European country is there a minority that is as poor, relative to the rest of the population, as blacks in the United States. In 1999 the poverty rate among non-Hispanic whites in the United States was 7.7 percent, compared with 23.6 percent among blacks. Non-Hispanic whites made up 70.7 percent of the U.S. population but only 46.1 percent of the poor; in metropolitan areas, fewer than 40 percent of the poor were non-Hispanic whites. Thus any incomebased transfer scheme will disproportionately transfer income to African-Americans, Hispanics, and other minority races. If people dislike transferring money to people of a different color, this could possibly explain the redistribution gap between the United States and Europe. ${ }^{79}$

We use several methods to quantify this hypothesis. First, we look at racial heterogeneity across countries. Table 9 reports two regressions that start with the Persson and Tabellini specifications and introduce fractionalization measures. In both, the dependent variable is social spending as a share of GDP. In column 9-1 we add the now-standard measure of ethnolinguistic fractionalization widely used in the literature. ${ }^{80}$ This variable gives the probability that two randomly drawn individuals in the same country speak different languages. Although the raw relationship between this variable and redistribution is quite high (a correlation coefficient of 41 percent), when other controls are added the coefficient on this variable becomes insignificant.

Of course, this variable does not capture all instances of racial heterogeneity. To correct this problem, we constructed a new variable that cap-

79. The closest European equivalent to this phenomenon is anti-Arab feeling among the French or anti-Gypsy sentiment in Eastern Europe, where antipathy is aimed at extremely poor groups. The politics surrounding these groups supports the importance of race, as rightwing leaders (such as Jean-Marie LePen in France or Jörg Haider in Austria) emphasize their hostility to these poor minorities.

80. This variable is the same one used by Easterly and Levine (1997). See appendix B for more details. 
Table 9. Cross-Country Regressions Explaining Transfers with Ethnolinguistic and Racial Fractionalization ${ }^{\mathbf{a}}$

\begin{tabular}{lcc}
\hline Independent variable & $9-1$ & $9-2$ \\
\hline Ethnolinguistic fractionalization $^{\mathrm{b}}$ & -1.864 & \\
& $(2.863)$ & $-7.538^{*}$ \\
Racial fractionalization $^{\mathrm{c}}$ & & $(3.378)$ \\
& & 1.918 \\
GDP per capita & 0.402 & $(1.289)$ \\
& $(1.351)$ & 0.327 \\
Percent of population aged 15-64 & $0.628^{* *}$ & $(0.184)$ \\
& $(0.210)$ & -2.305 \\
Majoritarian regime dummy & & $(1.302)$ \\
& -1.381 & -0.092 \\
Asia dummy & $(1.502)$ & $(4.221)$ \\
& -1.770 & -2.981 \\
Caribbean dummy & $(3.273)$ & $(2.548)$ \\
& -4.508 & -2.416 \\
Latin America dummy & $(2.653)$ & $(1.847)$ \\
& -2.733 & \\
Summary statistic & $(1.812)$ & 55 \\
No. of observations & & 0.69 \\
$R^{2}$ & 56 & \\
\hline
\end{tabular}

Source: Authors' calculations using data for 1960-98 from Persson and Tabellini (2000).

a. The dependent variable for each specification is social spending as a share of GDP. All specifications include a constant (not reported). $t$ statistics are reported in parentheses. ${ }^{*}$ denotes significance at the 5 percent level, ${ }^{* *}$ at the 1 percent level.

b. Probability that two randomly selected individuals from a population speak different languages.

c. Probability that two randomly selected individuals from a population are of different races.

d. Equals one in a regime where all seats in a district are awarded to the party that wins the district.

tures differences in racial origin rather than language (see appendix B for data sources). In many cases the two coincide, but not always. For example, Belgium would be classified as a very fragmented country in terms of language but more uniform in terms of race. Latin America is much less uniform in terms of race than in terms of language. We obtained information about racial composition from the sources detailed in appendix B and created a new racial fragmentation variable. The correlation between this variable and redistribution is 66 percent.

The regression reported in column 9-2 adds this new variable, which turns out to be significant at the 5 percent level. The majoritarian regime variable still has the expected negative sign (but is still insignificant). Figure 4 displays the relationship between the dependent variable and our measure of racial fractionalization. The United States is not far from the 
Figure 4. Relationship between Social Spending and Racial Fractionalization

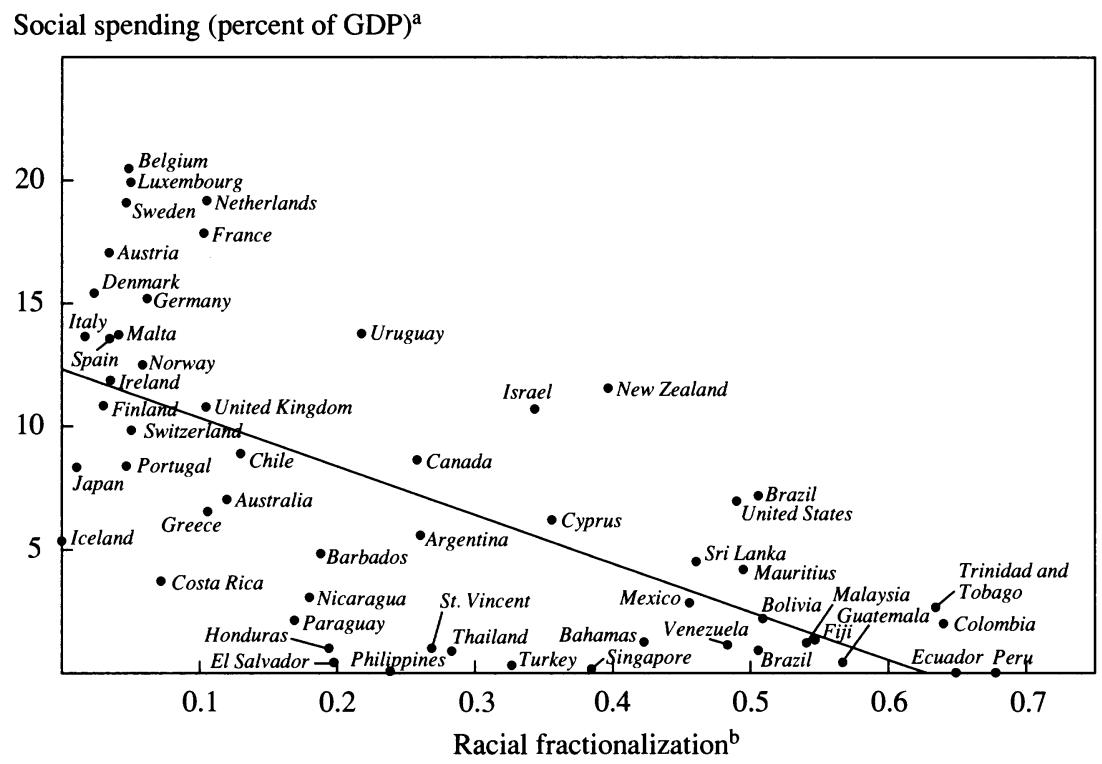

Source: Authors' calculations based on data from Persson and Tabellini (2000).

a. Average for 1960-98.

b. Probability that two randomly selected individuals from a population are of different races. Measured over 1990-98.

regression line. The European countries are racially very homogeneous and, as we know, have a large measure of social spending. ${ }^{81}$

We also used micro evidence on this topic from the General Social Survey. This survey, used by Luttmer and by Alesina and La Ferrara to address related issues, provides annual data on between 1,200 and 2,400 people from 1972 to the present (see appendix B for details). We focus on the survey question that asks whether the state should spend more on welfare. Possible answers are that the state should spend more, spend about the same amount, or spend less; we quantify these answers by assigning

81. Note that the strong inverse correlation observed in figure 4 is not an artifact of failing to control for income per capita. In fact, an even stronger correlation would appear if one plotted the residual of a regression of SSI benefits against income per capita against our measure of racial fragmentation. 
them scores of $1,1 / 2$, and 0 , respectively. This question has been asked in most survey years and seems to provide the best information available on people's desires for more welfare.

Importantly, this question is difficult to use even in time-series comparisons within the United States. Since the question asks people about ideal spending on welfare relative to current spending, it is not appropriate for comparisons when the level of current spending has changed. Crosscountry comparisons are obviously impossible. A Swede who opposes more spending on welfare in Sweden is not the same as a Texan who opposes more spending on welfare in Texas. The Swede's answer to the question obviously reflects the already high welfare spending in that country.

However, we present in table 10 results using, as the dependent variable, answers to this question for the United States in a single period. The regression reported in column 10-1 shows the basic results for the entire sample (covering 1972-98), which mirror those of Luttmer. ${ }^{82}$ There is a large, negative income effect. The impact of education is nonmonotonic: high school dropouts want more welfare spending than do high school graduates, but people with graduate degrees favor increased welfare spending even more than do high school dropouts. The pro-welfare orientation of the highly educated is an interesting phenomenon that fits with stereotypes but is still not well understood. People in big cities appear to be much more pro-welfare, probably because people in those cities are more likely to live around the poor. Finally, there are weak effects of age (results not reported) and marital status. The gender of respondents is not found to matter at all.

Instead, the single largest coefficient in the regression is that on race. African-Americans are 23 percent more likely than other respondents to say that welfare spending should be increased. Although we are not surprised that blacks support welfare spending more than whites-race could well be correlated with permanent income, for example-the magnitude of the coefficient suggests that the impact of race on the desire for redistribution is far greater than any income effect. These results are very consistent with those of Alesina and La Ferrara, who look at a different question from the same survey concerning support for government redistribution to fight income inequality. ${ }^{83}$ These authors find similarly that whites are

82. Luttmer (2001).

83. Alesina and La Ferrara (2001). 
Table 10. Explaining Support for Welfare in the United States with Racial Variables ${ }^{\mathbf{a}}$

\begin{tabular}{lcccc}
\hline Independent variable & $10-1$ & $10-2$ & $10-3$ & $10-4$ \\
\hline Black & $0.232^{* *}$ & & & \\
& $(28.55)$ & & & \\
Income & $-0.020^{* *}$ & $-0.019^{* *}$ & $-0.022^{* *}$ & $-0.018^{* *}$ \\
& $(19.78)$ & $(17.19)$ & $(5.36)$ & $(13.54)$ \\
Female & 0.007 & 0.009 & 0.032 & 0.010 \\
& $(1.35)$ & $(1.67)$ & $(1.94)$ & $(1.39)$ \\
Married & $-0.033^{* *}$ & $-0.038^{* *}$ & -0.016 & $-0.036^{* *}$ \\
& $(5.82)$ & $(6.19)$ & $(0.91)$ & $(4.58)$ \\
No. of children & $0.006^{* *}$ & $0.006^{* *}$ & 0.010 & $0.007^{* *}$ \\
& $(3.96)$ & $(3.38)$ & $(1.77)$ & $(3.04)$ \\
High school education or less & $0.042^{* *}$ & $0.042^{* *}$ & -0.010 & $0.048^{* *}$ \\
& $(5.84)$ & $(5.56)$ & $(0.38)$ & $(5.08)$ \\
Some college education & -0.002 & -0.002 & -0.005 & 0.003 \\
& $(0.28)$ & $(0.28)$ & $(0.21)$ & $(0.26)$ \\
College graduate & $0.031^{* *}$ & $0.030^{* *}$ & 0.029 & $0.025^{*}$ \\
& $(3.62)$ & $(3.40)$ & $(1.16)$ & $(2.22)$ \\
Beyond college & $0.106^{* *}$ & $0.107^{* *}$ & $0.080^{*}$ & $0.133^{* *}$ \\
& $(8.76)$ & $(8.65)$ & $(2.47)$ & $(8.20)$ \\
Population of home city, & $0.010^{* *}$ & $0.010^{* *}$ & $0.011^{* *}$ & $0.010^{* *}$ \\
in logarithms & $(7.77)$ & $(7.21)$ & $(2.61)$ & $(5.90)$ \\
Ratio of blacks to total state & & -0.044 & & \\
population & & $(1.14)$ & & \\
Believe that blacks are lazy & & & $-0.030^{* *}$ & \\
& & & $(4.27)$ & \\
Had a black person over for & & & & $0.043^{* *}$ \\
dinner recently & & & & \\
Summary statistic & & & & \\
No. of observations & & & & \\
$R^{2}$ & 0.10 & 0.04 & 0.04 & 0.05 \\
\hline
\end{tabular}

Source: Authors' calculations using data for 1972-98 from the General Social Survey (see appendix B).

a. The dependent variable for each specification is respondents' opinions on the current level of welfare spending in their state; possible responses were "too much" (scored as 1), "about right" (scored as $1 / 2$ ), or "too little" (scored as 0 ). Regressions 10-2 through 10-4 use data from white respondents only. All specifications include a constant (not reported). $t$ statistics are reported in parentheses. * denotes significance at the 5 percent level, ** at the 1 percent level.

b. Measured on a scale from 0 to 7 , where 7 indicates strongest belief.

much less likely than nonwhites to support such redistribution, and this effect is of a magnitude similar to that reported above.

In column 10-2, we look at support for welfare among whites only, to see whether the results further support the importance of race. The regression also looks at the impact of the share of blacks in the population of the respondent's state of residence. The theory suggests that whites in more heterogeneous states should be less likely to support welfare. We find 
evidence that points in this direction, but the effect is weak and not statistically significant.

In column 10-3 we look at whether whites who believe that blacks are lazy are less likely to support welfare. A link between this measure of racial prejudice and support for welfare is made by Martin Gilens. ${ }^{84}$ This survey question should be interpreted as an attempt to get at both racial prejudice and, in particular, opinions about why blacks tend to be relatively poor. We again find that an effect is present but weak, perhaps because people do not answer the question honestly.

In column 10-4 we look for a correlation between personal acquaintance with blacks and support for welfare, using the following survey question: "During the last few years, has anyone in your family brought a friend who was an African American home for dinner?" Only 27 percent of whites say that they have. Naturally, this variable could reflect both contact or lack of contact with blacks and underlying hostility or lack thereof toward blacks. People who have had blacks over to dinner are indeed more likely to support increased welfare; there is also a weakly negative connection between this personal acquaintance variable and belief that blacks are lazy (results not shown).

As a final check, we look at the relationship across states between racial heterogeneity and the generosity of welfare payments. To avoid problems associated with welfare reform in the mid-1990s, we use data for 1990. Under the AFDC program then in existence, as under the TANF program today, states have discretion in the way they structure their welfare payments, and there was and is considerable heterogeneity in the generosity of these programs. The dependent variable is the maximum monthly AFDC payment to a family of three. The explanatory variable is the share of the population that is black. If our theory is correct, states with more AfricanAmerican residents should have less generous programs.

Figure 5 shows that this is the case. There is a strong negative relationship between the generosity of a state's program and the share of the state's population that is black: the raw correlation is 49 percent. It is worth emphasizing that, in all fifty states, blacks are a minority of the population, and in all fifty they are disproportionately represented among the poor. One possible confound in this relationship is the average income of the state: states with a larger share of blacks tend to be poorer and may offer less generous payments for that reason. However, when we regress the

84. Gilens (1999). 
Figure 5. Relationship between Welfare Benefit and the Black Population Share, by State, 1990

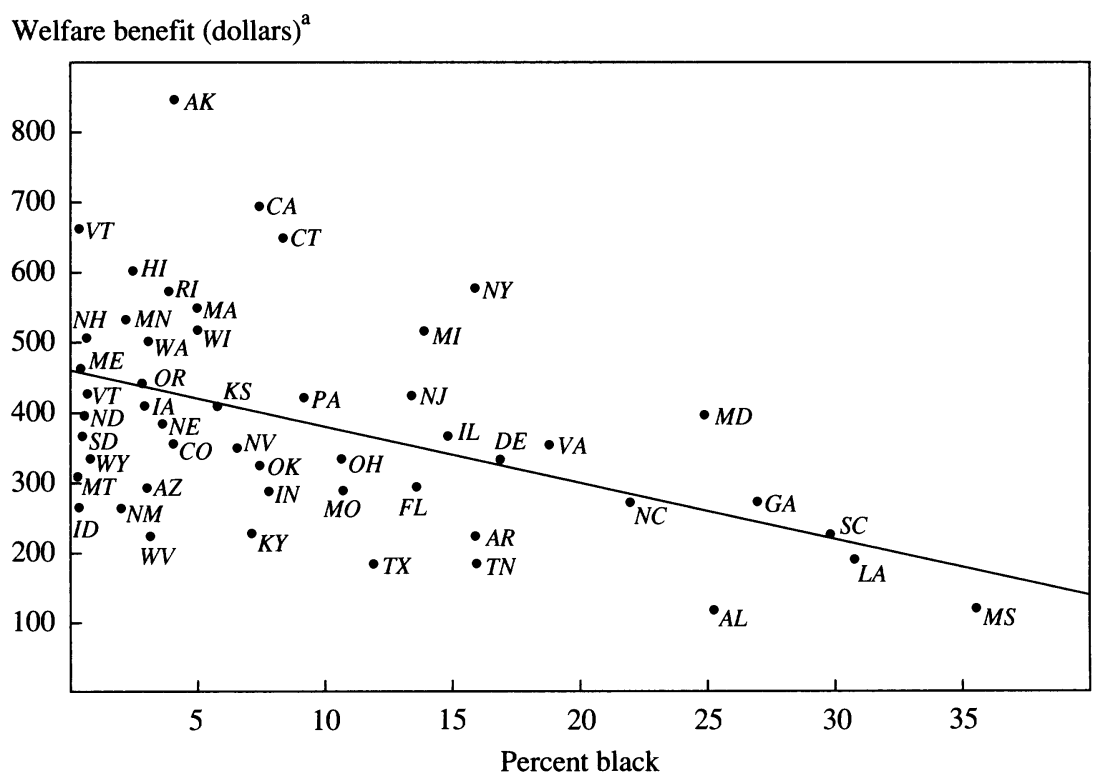

Source: Authors' calculations based on data from the General Social Survey (see appendix B for details) and U.S. Government Printing Office, 1998 Green Book.

a. Maximum monthly AFDC benefit for a family of three.

maximum AFDC payment on both state median income and the share of the state population that is black, our primary result is still significant. The estimated regression is (standard errors are in parentheses)

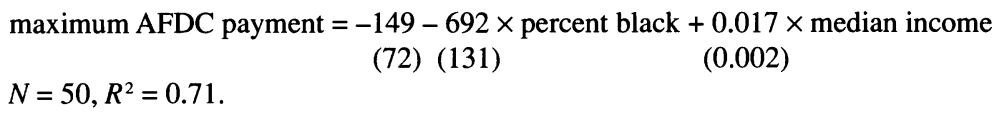

These coefficients indicate that a 1 percentage point change in the share of the population that is black reduces the maximum monthly AFDC payment by $\$ 6.92$, and a $\$ 1,000$ increase in median income increases the maximum payment by $\$ 17$. These results confirm the strong connection between racial homogeneity and redistribution.

Overall, the cross-country evidence, the cross-state evidence (both that of Alesina, Baqir, and Easterly and the work presented here), and the survey evidence given here (and that of Luttmer and of Alesina and La 
Ferrara) all suggest that hostility between races limits support for welfare. It is clear that racial heterogeneity within the United States is one of the most important reasons why the welfare state in America is small.

RECIPROCAL ALTRUISM. A final possible explanation of Europe-U.S. differences in redistribution is reciprocal altruism. This simple idea is generally credited to Robert Trivers, who argued that animals evolved to respond in kind to the actions of others; that is, a tit-for-tat policy is simple and generally optimal. ${ }^{85}$ Mathew Rabin presents an economic model showing reciprocal altruism in action, and Paul Romer uses the taste for vengeance (a specific form of reciprocal altruism) to understand the politics surrounding Social Security. ${ }^{86}$

Reciprocal altruism relates to welfare because anti-welfare forces generally try to emphasize that welfare recipients are taking money from taxpayers rather than working to earn a living. (A classic example is Ronald Reagan's apocryphal welfare queen living high on taxpayer dollars.) Since the 1960s, anti-welfare politicians have emphasized the claim that the poor are unworthy of public charity and are cheating the system. It is easy to see why the nonworking poor who receive income from working taxpayers might generate resentment and hostility. It is less easy to understand why this force might differ between the United States and Europe.

One thing, however, is clear. Opinions about the poor differ sharply between the United States and Europe. In Europe the poor are generally thought to be unfortunate, but not personally responsible for their own condition. For example, according to the World Values Survey, whereas 70 percent of western Germans express the belief that people are poor because of imperfections in society, not their own laziness, 70 percent of Americans hold the opposite view. Responding to another World Values Survey question, which asked whether poor people could work their way out of poverty, 71 percent of Americans but only 40 percent of Europeans said that they could (see table 13 below). Most Americans essentially believe that anyone can work his or her way out of poverty by dint of hard work, and that the poor remain poor only because they refuse to put in this effort. Given these beliefs, it is not surprising that Americans think that

85. Trivers (1971). Obviously, simple tit-for-tat policies will not dominate complete rationality-in the absence of reputation concerns. However, for nonhuman primates (and perhaps even for humans), evolution may have trouble creating complete rationality.

86. Rabin (1993); Romer (1996). 
the poor are undeserving of welfare, whereas Europeans think that the poor are unfortunate and therefore deserving of welfare. ${ }^{87}$

We therefore repeated the cross-country regressions in table 9 with an additional variable: the country mean of the percentage who believe that income differences across individuals are driven by luck. This variable has a significant positive coefficient, indicating that the more people believe that luck drives success, the larger is the share of social spending. This holds even after controlling for all the other right-hand-side variables in table 9, although complete data on these variables are available for only twenty-nine countries. ${ }^{88}$

Indirect evidence on American attitudes toward the poor can also be taken from a paper by Alesina, Rafael Di Tella, and Robert MacCulloch, which examines the determinants of happiness in the United States and Europe ${ }^{89}$ The authors find that most of the individual characteristics examined influence happiness in almost identical ways on both sides of the Atlantic. However, whereas more Europeans become less happy as inequality in their country rises, the happiness of Americans is unrelated to inequality in their state of residence.

What forces might be responsible for these differences in beliefs? We can only speculate at this point, but there are a plethora of plausible explanations. First, such beliefs might reflect an underlying reality. As table 11 shows, there is a strong positive correlation between earnings and hours worked in the United States. The median American male aged twentyfive to fifty-four in the top income quintile works forty-five hours a week, and the average for this group is forty-eight hours a week. Both of these numbers are markedly higher than those for all other income quintiles. Young American males in the bottom quintile work only twenty-seven hours a week on average. Even when the sample is restricted to full-time workers (results not shown), it remains true that poorer U.S. workers work far fewer hours. These patterns are less common in Europe. For example, in Switzerland and Italy, men in the bottom income quintile work more hours than men in the top quintile. In Sweden, the median worker works

87. Lipset (1996) reports results from various polls, all of which suggest that an overwhelming majority believe that the poor can lift themselves out of poverty if they try hard enough.

88. These results are not reported here but are available from the authors upon request.

89. Alesina, Di Tella, and MacCulloch (2001). 
Table 11. Hours Worked in Selected OECD Countries, by Income ${ }^{a}$

Median/mean

\begin{tabular}{lccccccc}
\hline $\begin{array}{l}\text { Income } \\
\text { quintile }\end{array}$ & $\begin{array}{c}\text { France, } \\
1994\end{array}$ & $\begin{array}{c}\text { Germany, } \\
1994\end{array}$ & $\begin{array}{c}\text { Italy, } \\
1995\end{array}$ & $\begin{array}{c}\text { Nether- } \\
\text { lands, } \\
1994\end{array}$ & $\begin{array}{c}\text { Sweden, } \\
1995\end{array}$ & $\begin{array}{c}\text { Switzer- } \\
\text { land, } \\
1992\end{array}$ & $\begin{array}{c}\text { United } \\
\text { States, } \\
1997\end{array}$ \\
\hline First (lowest) & $39 / 38$ & $12 / 26$ & $50 / 50$ & $0 / 16$ & $39 / 35$ & $55 / 62$ & $35 / 27$ \\
Second & $39 / 41$ & $40 / 39$ & $40 / 41$ & $40 / 35$ & $39 / 38$ & $44 / 50$ & $40 / 42$ \\
Third & $39 / 41$ & $40 / 41$ & $40 / 40$ & $40 / 40$ & $39 / 39$ & $42 / 46$ & $40 / 44$ \\
Fourth & $39 / 42$ & $40 / 42$ & $40 / 40$ & $40 / 41$ & $39 / 39$ & $42 / 46$ & $40 / 45$ \\
Fifth & $45 / 47$ & $44 / 45$ & $40 / 42$ & $40 / 44$ & $39 / 40$ & $45 / 50$ & $45 / 48$ \\
\hline
\end{tabular}

Source: Luxembourg Income Study data.

a. By males aged 25-54.

thirty-nine hours a week in all income quintiles. Other countries have patterns that are somewhat closer to that of the United States.

The perception in the United States of a close connection between effort and income or wealth has deep historical roots. It was noted by Alexis de Tocqueville, who contrasted it strongly with the European association of indolence with the aristocracy. For example, he wrote, "It is to escape this obligation of work that so many rich Americans come to Europe; there they find the debris of aristocratic societies among which idleness is still honored. ${ }^{\circ 0}$ At the extreme, it is still true that the richest person in America is the self-made chairman of Microsoft, Bill Gates, but the richest people in England are Queen Elizabeth and the Duke of Westminster.

Second, it is entirely possible that Americans have inherited an ethos of hard work from their Puritan antecedents, and Americans still seem to think that laziness is something of a sin. The Congregationalists who settled New England were intellectual descendants of Calvin, and Calvinist views are still heard in the United States. De Tocqueville describes the American work ethos in these terms: "[An American] would deem himself disreputable if he used his life only for living." Current survey evidence still supports this pro-work orientation. For example, in the General Social Survey only 22 percent of respondents agreed that a job is just a way of earning money, and 63 percent said that they would enjoy having a paying job even if they did not need the money.

A third factor is that Americans might in general be more comfortable than Europeans with punishing miscreants, and therefore might be more amenable

90. De Tocqueville (1835). 
to the idea of punishing welfare recipients by cutting back on welfare. The view that Americans are more comfortable with punishment, and in particular with punishing the less fortunate, than Europeans has some basis in fact. For example, the General Social Survey asked whether respondents thought that the courts in their country punished criminals too harshly or not harshly enough. Eighty-six percent of U.S. respondents said that the courts are not harsh enough, and only 4 percent that the courts are too harsh. Americans overwhelmingly support the death penalty. The United States, as already noted, spends more per capita on defense than do the European countries, and Americans are generally more enthusiastic than Europeans about wars (or have been since World War II at least). Richard Nisbet and Dov Cohen suggest that an American taste for retribution might have come from the frontier and the need to protect goods when property rights are uncertain. ${ }^{91}$ In contrast, two disastrous world wars fought on their homelands, together with awful experiences with punitive fascist regimes, may have discredited the use of vengeful punishment among Europeans.

A fourth possibility is that the view of welfare recipients as lazy (or even cheaters) is endogenous and rooted in the social isolation of the poor in the United States. If Europeans are more likely to know welfare recipients (both because European society is relatively more integrated and because there are more welfare recipients to get acquainted with), they might react negatively to aspersions cast on their integrity. In the United States, where welfare recipiency is rarer, it might be easier for anti-welfare leaders to malign the character of welfare recipients. Naturally, this creates a situation of increasing returns, whereby the ability to promote the expansion of a welfare state increases as the welfare state itself grows.

Table 12 presents our first evidence on mobility and support for welfare, using data from the General Social Survey. The regression reported in column 12-1 estimates the connection between occupational mobility and support for more spending on welfare. Occupational mobility is defined as the mean difference in occupational prestige between the respondent and his or her father. We take the mean of this respondent-father difference by race and by occupation group. (We separate out the races because it may well be that attitudes about mobility are formed only on the basis of one's own race.) We find a significant negative effect of occupational mobility on support for welfare. This supports the idea that people who have them-

91. Nisbett and Cohen (1996). 
Table 12. Explaining Support for Welfare in the United States with Income Mobility and Behavioral Variables ${ }^{\mathrm{a}}$

\begin{tabular}{lccc}
\hline Independent variable & $12-1$ & $12-2$ & $12-3$ \\
\hline Black & $0.260^{* *}$ & $0.202^{* *}$ & $0.245^{* *}$ \\
& $(25.39)$ & $(22.89)$ & $(29.25)$ \\
Income & $-0.016^{* *}$ & $-0.018^{* *}$ & $-0.020^{* *}$ \\
& $(11.74)$ & $(17.17)$ & $(19.85)$ \\
Female & 0.001 & -0.001 & $0.012^{*}$ \\
& $(0.19)$ & $(0.10)$ & $(2.30)$ \\
Married & $-0.034^{* *}$ & $-0.031^{* *}$ & $-0.030^{* *}$ \\
& $(4.55)$ & $(5.16)$ & $(5.19)$ \\
No. of children & $0.005^{* *}$ & $0.006^{* *}$ & 0.007 \\
& $(2.83)$ & $(3.49)$ & $(4.23)$ \\
High school education or less & $0.038^{* *}$ & $0.036^{* *}$ & $0.040^{* *}$ \\
& $(4.41)$ & $(4.75)$ & $(5.57)$ \\
Some college education & 0.012 & -0.008 & -0.002 \\
& $(1.37)$ & $(1.03)$ & $(0.23)$ \\
College graduate & $0.050^{* *}$ & $0.015^{* *}$ & $0.032^{* *}$ \\
& $(4.13)$ & $(1.65)$ & $(3.84)$ \\
Beyond college & $0.144^{* *}$ & $0.082^{* *}$ & $0.106^{* *}$ \\
Population of home city, & $(7.87)$ & $(6.43)$ & $(8.74)$ \\
in logarithms & $0.009^{* *}$ & $0.008^{* *}$ & $0.008^{* *}$ \\
Mean occupational mobility & $(7.04)$ & $(6.29)$ & $(6.48)$ \\
& $-0.002^{* *}$ & & \\
Supports capital punishment & $(6.44)$ & & \\
Frequency of church attendance & & & \\
Protestant & & $(15.13)$ & \\
Summary statistic & & & $-0.041^{* *}$ \\
No. of observations & & & $(5.08)$ \\
$R^{2}$ & & & $-0.025^{* *}$ \\
\hline
\end{tabular}

Source: Authors' calculations using data for 1972-98 from the General Social Survey (see appendix B).

a. The dependent variable for each specification is respondents' opinions on the current level of welfare spending in their state; possible responses were "too much" (scored as 1), "about right" (scored as 1/2), or "too little" (scored as 0). All specifications include a constant (not reported), $t$ statistics are reported in parentheses. ${ }^{*}$ denotes significance at the 5 percent level, ${ }^{* *}$ at the 1 percent level.

b. The mean difference in occupational prestige between the respondent and his or her parent in a given race and given occupation group.

c. Number of times a week.

selves risen from poverty are more likely to think that the poor can do likewise, and therefore are only on welfare because they are lazy or cheating the system. Of course, this relationship might also arise because greater mobility is associated with higher future wage growth, as discussed in the section on economic determinants above. ${ }^{92}$

92. This point is investigated by Alesina and La Ferrara (2001). 
Column 12-2 reports results of a regression that examines the relationship between support for capital punishment and welfare. This regression tests the notion that people who are more comfortable with retribution are more likely to oppose giving money to the poor. We find an extremely strong relationship in the United States between supporting capital punishment and opposing welfare. The unexpectedly high correlation between these opinions (16 percent) may seem hardly natural. However, it makes sense if opposition to welfare comes from a desire to punish people who are seen as stealing from taxpayers.

Column 12-3 considers the hypothesis that Protestantism is an important force driving beliefs about the poor and about welfare: support for increased welfare is regressed on church attendance and on being a Protestant. Both variables have a statistically significant effect. More-religious Americans, and Protestant Americans, are more likely to oppose increased spending on welfare. Protestantism is also linked to the belief that success results from effort.

To investigate these issues further, we again use the World Values Survey to examine the distribution of opinions in Europe and the United States. As argued earlier, support for a country's current welfare policies makes little sense as a variable for cross-country comparisons. Instead, we use left-wing political attitudes as our best proxy for attitudes toward the poor. Within countries the correlation between support for welfare and left-wing status is considerable. The mean difference in the proportion of respondents who are left-wing is 13 percent ( 30 percent of Europeans versus 17 percent of Americans describe themselves as left-wing).

Table 13 reports a decomposition of American and European responses to three questions about the poor: whether the poor are trapped in poverty, whether luck determines income, and whether the poor are lazy. As discussed earlier, the table shows the large differences between the United States and Europe in the responses to these questions. For example, 54 percent of Europeans believe that the poor are unlucky, whereas only 30 percent of Americans share that belief.

Table 13 also shows the connection between these variables and leftwing self-identification. The connection between believing that the poor are trapped and left-wing attitudes is strong in the United States: Americans who describe themselves as left-wing make up 26 percent of those who believe the poor are trapped in their poverty, but only 14 percent of those who hold the contrary view. The difference in left-wing orientation 
Table 13. Relationship between Leftist Political Orientation and Beliefs about the Poor

Percent

\begin{tabular}{llc}
\hline Item & European Union & United States \\
\hline Identify themselves as on the left of & 30 & 17 \\
political spectrum & 60 & 29 \\
Believe poor are trapped in poverty & 34 & 26 \\
Percent of the above who are on the left & 40 & 71 \\
Do not believe poor are trapped in poverty & 27 & 14 \\
Percent of the above who are on the left & 54 & 30 \\
Believe luck determines income & 35 & 18 \\
Percent of the above who are on the left & 46 & 70 \\
Do not believe luck determines income & 25 & 16 \\
Percent of the above who are on the left & 26 & 60 \\
Believe the poor are lazy & 23 & 11 \\
Percent of the above who are on the left & 74 & 40 \\
Do not believe the poor are lazy & 34 & 25 \\
Percent of the above who are on the left &
\end{tabular}

Source: Authors' calculations based on data for 1981-97 from the World Values Survey (see appendix B).

between the United States and Europe drops from 13 percentage points to 8 percentage points within the group that agrees that the poor are trapped. There is no drop among those who believe that the poor are not trapped.

The connection between belief in luck as a determinant of poverty and left-wing self-identification is weaker in the United States than in Europe. Sixteen percent of Americans who say that success is due to effort, and 18 percent of those who say it is due to luck, are self-described leftwingers. This is not much of a difference. In Europe the comparable numbers are 25 percent and 35 percent. Although there is a huge difference between the United States and Europe in belief in the role of luck, it is not the case that holding belief in the role of effort constant eliminates the U.S.-Europe difference in left-wing self-identification.

Table 13 also looks at beliefs about whether the poor are lazy. Again, there is a very large difference between the United States and Europe. Sixty percent of American respondents, but only 26 percent of Europeans, say that the poor are lazy. However, at the individual level there is little connection between this variable and left-wing self-identification. Holding constant belief in whether the poor are lazy causes the difference in leftwing self-identification to drop from 13 percentage points to between 9 and 12 percentage points. These effects are not all that large. 
As a third test, we regress transfers divided by GDP on the share of the respondents in the country who say that success is due to luck rather than effort. Figure 6 shows the relationship graphically. In this cross-country sample the two variables have a correlation of 0.44 .

Table 14 looks at the determinants of left-wing attitudes using data across countries from the World Values Survey. We interpret this variable as reflecting something like beliefs about welfare, which should abstract from the effect of political institutions. In column 14-1 we present results of a basic regression that includes the U.S. dummy variable and controls for individual characteristics such as age and race. We observe no impact of these controls on the U.S. dummy: its coefficient of -0.125 corresponds to the roughly 13-percentage-point difference in left-wing status between the United States and Europe discussed earlier. Variables that can explain

Figure 6. Relationship between Social Spending and Belief That Luck Determines Income

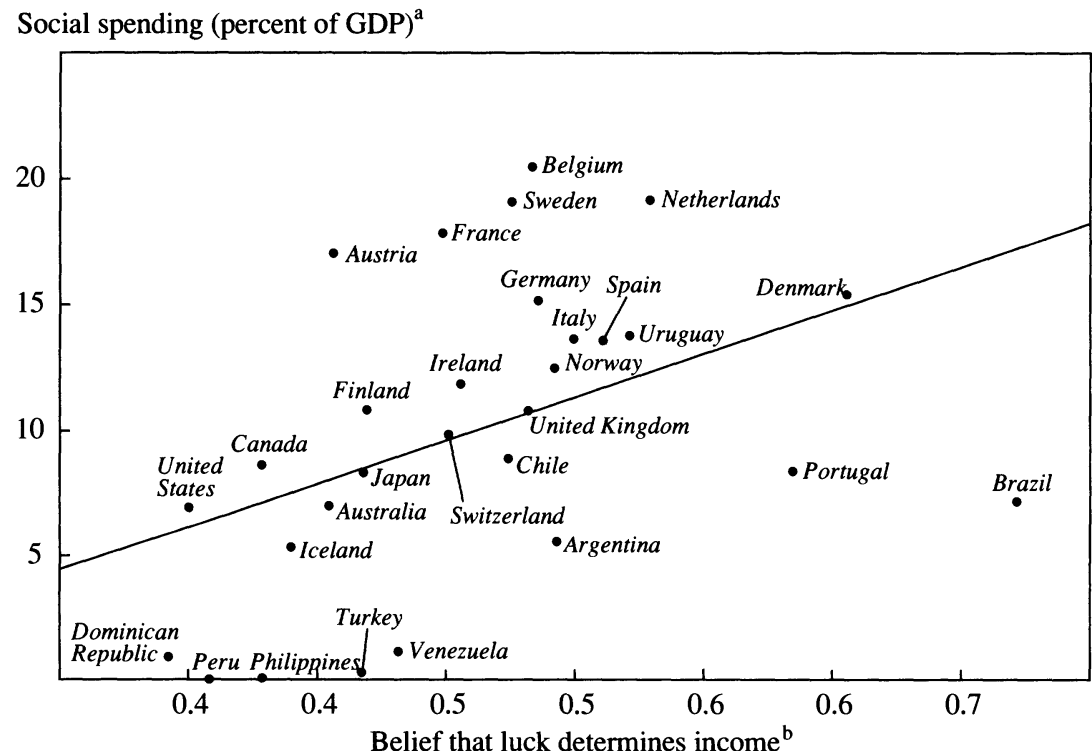

Source: Authors' calculations based on data from the World Values Survey.

a. Average for 1960-98.

b. Mean value for country, measured as an index from 1 to 10 , with 10 indicating strongest belief. Data for $1981-97$. 
Table 14. Regressions Explaining Leftist Political Orientation ${ }^{\mathrm{a}}$

\begin{tabular}{|c|c|c|c|c|}
\hline Independent variable & $14-1$ & $14-2$ & $14-3$ & $14-4$ \\
\hline U.S. resident & $\begin{array}{l}-0.125^{* *} \\
(12.14)\end{array}$ & $\begin{array}{l}-0.007 \\
(0.02)\end{array}$ & $\begin{array}{l}-0.096 * * \\
(3.31)\end{array}$ & $\begin{array}{r}0.047 \\
(0.25)\end{array}$ \\
\hline Income & $\begin{array}{l}-0.010 * * \\
(7.20)\end{array}$ & $\begin{array}{l}-0.010^{*} \\
(2.38)\end{array}$ & $\begin{array}{l}-0.009 * \\
(3.78)\end{array}$ & $\begin{array}{l}-0.010^{* *} \\
(4.00)\end{array}$ \\
\hline Years of education & $\begin{array}{l}-0.004^{* *} \\
(3.79)\end{array}$ & $\begin{array}{l}-0.004 * * \\
(1.09)\end{array}$ & $\begin{array}{l}-0.002 \\
(0.74)\end{array}$ & $\begin{array}{l}-0.001 \\
(0.34)\end{array}$ \\
\hline City population & $\begin{array}{l}0.010^{* *} \\
(7.43)\end{array}$ & $\begin{array}{l}0.010^{*} \\
(2.36)\end{array}$ & $\begin{array}{l}0.010^{* *} \\
(4.29)\end{array}$ & $\begin{array}{l}0.010 * * \\
(4.13)\end{array}$ \\
\hline White & $\begin{array}{l}0.036^{* *} \\
(4.83)\end{array}$ & $\begin{array}{l}0.029 \\
(1.45)\end{array}$ & $\begin{array}{l}0.051 * * \\
(3.13)\end{array}$ & $\begin{array}{l}0.041^{*} \\
(2.57)\end{array}$ \\
\hline Married & $\begin{array}{l}-0.026^{* *} \\
(3.22)\end{array}$ & $\begin{array}{l}-0.025^{*} \\
(2.29)\end{array}$ & $\begin{array}{l}-0.030 * * \\
(2.97)\end{array}$ & $\begin{array}{l}-0.029 * * \\
(2.79)\end{array}$ \\
\hline No. of children & $\begin{array}{l}-0.009 * * \\
(3.63)\end{array}$ & $\begin{array}{l}-0.010 \\
(1.82)\end{array}$ & $\begin{array}{l}-0.010 * * \\
(3.09)\end{array}$ & $\begin{array}{l}-0.011 * * \\
(3.08)\end{array}$ \\
\hline Female & $\begin{array}{l}-0.044^{* *} \\
(6.93)\end{array}$ & $\begin{array}{l}-0.042^{* *} \\
(3.57)\end{array}$ & $\begin{array}{l}-0.043 * * \\
(3.43)\end{array}$ & $\begin{array}{l}-0.041^{* *} \\
(3.28)\end{array}$ \\
\hline Racial fractionalization $^{b}$ & & $\begin{array}{r}-0.275 \\
(0.33)\end{array}$ & & $\begin{array}{c}-0.298 \\
(0.73)\end{array}$ \\
\hline $\begin{array}{l}\text { Mean belief that luck } \\
\text { determines income }^{\mathrm{c}}\end{array}$ & & & $\begin{array}{l}0.541^{* *} \\
(3.69)\end{array}$ & $\begin{array}{l}0.655^{* *} \\
(3.74)\end{array}$ \\
\hline \multicolumn{5}{|l|}{ Summary statistic } \\
\hline No. of observations & 20,269 & 19,265 & 16,478 & 15,489 \\
\hline$R^{2}$ & 0.03 & 0.03 & 0.03 & 0.03 \\
\hline
\end{tabular}

Source: Authors' calculations using data for 1981-97 from World Values Survey (see appendix B).

a. The dependent variable for each specification is a dummy variable that equals one when a respondent identifies himself or herself as being on the left of the political spectrum. All specifications include a constant and dummies for age categories (not reported). Absolute values of robust $\mathrm{t}$ statistics are reported in parentheses. $*$ denotes significance at the 5 percent level, ** at the 1 percent level.

b. Probability that two randomly selected individuals from a population are of different races.

c. See appendix B for details.

this difference in attitudes toward redistribution will cause this difference to drop.

The regression in column 14-2 controls for racial fractionalization in the country, using the same racial variable discussed earlier. This variable is available only at the country level, and therefore we control for withincountry correlation of the error terms. The coefficient on this variable is quite large, but statistically insignificant. It also eliminates the coefficient on the U.S. dummy. This could be interpreted as indicating that racial heterogeneity may explain the entire difference in left-wing attitudes between the United States and Europe, but our statistical confidence in this claim is weak. 
The regression in column 14-3 controls for the belief that luck determines income. Because we are quite wary about looking at the relationship between two individual-specific variables (left-wing self-identification and beliefs about luck) that may really be the same thing, we have used the within-occupation, within-country mean belief that luck determines income. The logic of this is that the occupation group average may represent the outside influence that affects peoples' beliefs but will not be quite as endogenous as the respondents' own beliefs. This has a sizable effect on the U.S. dummy, reducing it by 20 percent. The regression in column 14-4 includes both racial heterogeneity and beliefs about luck versus effort.

Our conclusion from this section is that we are very confident that race is critically important to understanding differences between the United States and Europe in attitudes toward welfare. It is also true that Americans generally think that income comes from effort and that welfare recipients are not pulling their weight. This opinion may itself be the outcome of racial factors.

\section{Conclusion}

Why is redistribution so much greater in Europe than in the United States? We have examined three sets of explanations, which we labeled economic, political, and behavioral. The economic explanations do not explain much of the puzzle. Before-tax income inequality is higher, and the income distribution appears to be more skewed, in the United States than in Europe. There does not appear to be more income uncertainty in Europe, nor is there evidence that the European tax system is more efficient. There may be more chance for upward mobility among politically powerful groups in the United States. Overall, we think that standard economic models of income redistribution do a poor job of explaining the differences between the United States and Europe.

On the other hand, political variables, including the electoral system (in particular, proportionality and, in the United States, the two-party system) and the role of the courts, are important. The two-party system and the lack of proportional representation in the United States created obstacles that blocked the formation of a strong and lasting socialist party. In contrast, the upheaval in continental Europe over the last century has 
meant that no durable institutions remained to protect property against popular demand for redistribution. Monumental differences in the history and geography of the two regions, such as the Civil War and the open frontier in the United States during the nineteenth century, contributed to a different climate and different attitudes toward the relationship between the individual and the state.

The behavioral explanations also seem very important. Racial fragmentation in the United States and the disproportionate representation of ethnic minorities among the poor clearly played a major role in limiting redistribution, and indeed, racial cleavages seem to serve as a barrier to redistribution throughout the world. This history of American redistribution makes it quite clear that hostility to welfare derives in part from the fact that welfare spending in the United States goes disproportionately to minorities. Another important difference is that Americans dislike redistribution because they tend to feel that people on welfare are lazy, whereas Europeans tend to feel that people on welfare are unfortunate. Apart from the fact that, in the United States, there is indeed a stronger connection between effort and earnings than in Europe, we do not know what explains these differences in beliefs.

Our bottom line is that Americans redistribute less than Europeans for three reasons: because the majority of Americans believe that redistribution favors racial minorities, because Americans believe that they live in an open and fair society and that if someone is poor it is his or her own fault, and because the political system is geared toward preventing redistribution. In fact, the political system is likely to be endogenous to these basic American beliefs.

\section{APPENDIX A}

\section{Proofs of Propositions}

Proof of Proposition 1: First, the impact of $\alpha$ and $\lambda$ are clearly the same, so it is sufficient to prove that redistribution is rising in $\alpha$. We use the following notation:

$$
Q\left(Y_{0}\right)=\int_{\varepsilon}\left[\delta \hat{Y}-Y\left(Y_{0}, \varepsilon\right)\right] U^{\prime}\left[(1-\tau) Y\left(Y_{0}, \varepsilon\right)+\tau \delta \hat{Y}\right] f(\varepsilon) g\left(Y_{0}\right) d \varepsilon .
$$


Taking the derivative of equation 4 yields

$$
\begin{aligned}
& \int_{Y_{0}}\left(\hat{Y}-Y_{0}\right) Q\left(Y_{0}\right)= \\
& -\frac{\partial \tau}{\partial \alpha} \int_{Y_{0}}\left[\alpha\left(Y_{0}\right)+\lambda\left(Y_{0}\right)\right] \times \\
& \int_{\varepsilon}\left[\delta \hat{Y}-Y\left(Y_{0}, \varepsilon\right)\right]^{2} U^{\prime \prime}\left[(1-\tau) Y\left(Y_{0}, \varepsilon\right)+\tau \delta \hat{Y}\right] f(\varepsilon) g\left(Y_{0}\right) d \varepsilon d Y_{0} .
\end{aligned}
$$

The term multiplying $\frac{\partial \tau}{\partial \alpha}$ is obviously negative, so it is sufficient to prove that the term on the left-hand side of the equation is positive.

We will prove this by contradiction, and we start by assuming that $\int_{Y_{0}}\left(\hat{Y}-Y_{0}\right) Q\left(Y_{0}\right)<0$, which implies that $\int_{Y_{0}>\delta \hat{Y}}\left(\hat{Y}-Y_{0}\right) Q\left(Y_{0}\right)<$ $-\int_{Y_{0}<\delta \hat{Y}}\left(\hat{Y}-Y_{0}\right) Q\left(Y_{0}\right)$. From equation 4 we know that

$$
\begin{aligned}
& \int_{Y_{0}>\delta \hat{Y}}\left[1+\alpha_{0}+\left(\hat{Y}-Y_{0}\right)(1+\alpha+\lambda)\right] Q\left(Y_{0}\right)= \\
& -\int_{Y_{0}<\delta \hat{Y}}\left[1+\alpha_{0}+\left(\hat{Y}-Y_{0}\right)(1+\alpha+\lambda)\right] Q\left(Y_{0}\right),
\end{aligned}
$$

and both sides of this equation are positive, since $\left[1+\alpha_{0}+\left(\hat{Y}-Y_{0}\right)\right.$ $(1+\alpha+\lambda)]>0$, and $Q\left(Y_{0}\right)>0$ for $Y_{0}>\delta \hat{Y}$ (which together imply that the left-hand side is positive, which in turn implies that the right-hand side is positive as well).

Equation A2 implies that $\int_{Y_{0}>\delta \hat{Y}} Q\left(Y_{0}\right)<-\int_{Y_{0}<\delta \hat{Y}} Q\left(Y_{0}\right)$, because $\left[1+\alpha_{0}+\left(\hat{Y}-Y_{0}\right)\right.$ $(1+\alpha+\lambda)]$ is declining in $Y_{0}$, which in turn implies $(1-\delta) \hat{Y} \int_{Y_{0}>\delta \hat{Y}} Q\left(Y_{0}\right)<$ $-(1-\delta) \hat{Y} \int_{Y_{0}<\delta \hat{Y}} Q\left(Y_{0}\right)$, and since $\hat{Y}-Y_{0}<(1-\delta) \hat{Y}$ for all $Y_{0}>\delta \hat{Y}$ and $\hat{Y}-Y_{0}>$ $(1-\delta) \hat{Y}$ for all $Y_{0}<\delta \hat{Y}$, this implies that $\int_{Y_{n}>\delta \hat{Y}}\left(\hat{Y}-Y_{0}\right) Q\left(Y_{0}\right)<-\int_{Y_{0}<\delta \hat{Y}}\left(\hat{Y}-Y_{0}\right) Q\left(Y_{0}\right)$ This contradicts $\int_{Y_{n}>\delta \hat{Y}}\left(\hat{Y}-Y_{0}\right) Q\left(Y_{0}\right)<-\int_{Y_{0}<\delta \hat{Y}}\left(\hat{Y}-Y_{0}\right) Q\left(Y_{0}\right)$. Thus it must be true that $\int_{Y_{0} \supset \delta \hat{Y}}\left(\hat{Y}-Y_{0}\right) Q\left(Y_{0}\right)<-\int_{Y_{0}<\delta \hat{Y}}\left(\hat{Y}-Y_{0}\right) Q\left(Y_{0}\right)$, and thus $\frac{\partial \tau}{\partial \alpha}$ is positive. 
Proof of Proposition 2: When $\theta=0$, equation $4 \mathrm{a}$ is positive if and only if $\delta>Y_{\text {Med }} / \hat{Y}$.

Proof of Proposition 3: For any parameter $X$ differentiation yields

$$
\begin{aligned}
& \frac{\partial \int\left[\delta \hat{Y}-Y_{\text {Med }}(\varepsilon)\right] U^{\prime}\left[(1-\tau) Y_{\text {Med }}(\varepsilon)+\tau \delta \hat{Y}\right] f(\varepsilon) d \varepsilon}{\partial X}= \\
& -\frac{\partial \tau}{\partial X} \int_{\varepsilon}\left[\delta \hat{Y}-Y_{\text {Med }}(\varepsilon)\right]^{2} U^{\prime \prime}\left[(1-\tau) Y_{\text {Med }}(\varepsilon)+\tau \delta \hat{Y}\right] f(\varepsilon) d \varepsilon .
\end{aligned}
$$

Since the terms multiplying $\frac{\partial \tau}{\partial X}$ are positive, the sign of $\frac{\partial \tau}{\partial X}$ will be determined by the sign of $\frac{\partial \int\left[\delta \hat{Y}-Y_{\text {Med }}(\varepsilon)\right] U^{\prime}\left[(1-\tau) Y_{\text {Med }}(\varepsilon)+\tau \delta \hat{Y}\right] f(\varepsilon) d \varepsilon}{\partial X}$. In the case of $\mu\left(Y_{M e d}\right)$, this equals

$$
\int_{\varepsilon}\left[-\theta U^{\prime}\left(Y_{N}(\varepsilon)\right]+\left[\delta \hat{Y}-Y_{\text {Med }}(\varepsilon)\right](1-\tau) \theta U^{\prime \prime}\left[Y_{N}(\varepsilon)\right] f(\varepsilon) d \varepsilon .\right.
$$

This can be rewritten as

$$
-\theta \int_{\varepsilon} U^{\prime}\left[Y_{N}(\varepsilon)\right]+Y_{N}(\varepsilon) U^{\prime \prime}\left\{Y_{N}(\varepsilon)-\delta \hat{Y} U^{\prime \prime}\left[Y_{N}(\varepsilon)\right]\right\} f(\varepsilon) d \varepsilon .
$$

Using the assumption that $U^{\prime}(Y)>-Y U^{\prime \prime}(Y)$, or $U^{\prime}(Y)+Y U^{\prime \prime}(Y)>0$, we know that the expression in the integral is strictly positive, and thus the entire term is negative. Thus the level of redistribution falls with $\mu\left(Y_{M e d}\right)$.

In the case of $\delta$ the left-hand side of equation A4 equals

$$
\int_{\varepsilon} \hat{Y} U^{\prime}\left[Y_{N}(\varepsilon)\right]+\left[\delta \hat{Y}-Y_{\text {Med }}(\varepsilon)\right] \hat{\tau} \hat{Y} U^{\prime \prime}\left[Y_{N}(\varepsilon)\right] f(\varepsilon) d \varepsilon,
$$

which can be rewritten as

$$
\begin{aligned}
& \int_{\varepsilon}\left\{\hat{Y} U^{\prime}\left[Y_{N}(\varepsilon)\right]+\hat{Y} U^{\prime \prime}\left[\left(Y_{N}(\varepsilon)\right]\right.\right. \\
& \left.-\left[(1-\tau \delta) \hat{Y}+\tau Y_{\text {Med }}(\varepsilon)\right] \hat{Y} U^{\prime \prime}\left[Y_{N}(\varepsilon)\right]\right\} f(\varepsilon) d \varepsilon .
\end{aligned}
$$


Again using $U^{\prime}(Y)+Y U^{\prime \prime}(Y)>0$, this term is positive, and thus redistribution will rise with $\delta$.

Finally, considering $\theta$, the left-hand side of equation A4 equals

$$
\begin{aligned}
& \int_{\varepsilon}\left\{-(\mu+\varepsilon) U^{\prime}\left[Y_{N}(\varepsilon)\right]+\right. \\
& \left.\left[\delta \hat{Y}-Y_{\text {Med }}(\varepsilon)\right](1-\tau)(\mu+\varepsilon) U^{\prime \prime}\left[Y_{N}(\varepsilon)\right]\right\} f(\varepsilon) d \varepsilon,
\end{aligned}
$$

where $\mu=\mu\left(Y_{\text {Med }}\right)-Y_{\text {Med }}$. Rewriting this equation yields

$$
\begin{aligned}
& \int_{\varepsilon}(\mu+\varepsilon)\left(-\left\{U^{\prime}\left[Y_{N}(\varepsilon)\right]+Y_{N}(\varepsilon) U^{\prime \prime}\left[Y_{N}(\varepsilon)\right]\right\}+\right. \\
& \left.\delta \hat{Y} U^{\prime \prime}\left[Y_{N}(\varepsilon)\right]\right) f(\varepsilon) d \varepsilon .
\end{aligned}
$$

If the variance of $\varepsilon$ equals zero, this term is clearly negative as long as $\mu>0$, so that more uncertainty leads to decreases in redistribution. Likewise, if $\mu$ is sufficiently negative, the term will be strictly positive, and more variation will lead to more redistribution. The problem is continuous, so that these claims will continue to hold for as long as the variance of $\varepsilon$ is low. If $\mu \geq 0$ and $\delta \hat{Y}=Y_{\text {Med }}(\varepsilon)$, the equation can be rewritten as

$$
\int_{\varepsilon}-(\mu+\varepsilon) U^{\prime}\left[Y_{N}(\varepsilon)\right] f(\varepsilon) d \varepsilon,
$$

which, from the concavity of $U(\cdot)$, is positive if $\varepsilon$ is symmetrically distributed, and thus more uncertainty leads to more redistribution.

\section{APPENDIX B}

\section{Data Sources}

\section{Government Revenue and Expenditure}

All reported measures, including historical data and those used to construct table 4, are for general government. Historical data are provided by Tanzi and Schuknecht (2000) for the 1870-1960 period and the 2000 OECD Economic Outlook database for the 1960-98 period. 


\section{Tax Rates}

The tax rates shown in figure 1 are based on comparative data published in OECD, Taxing Wages (2001). For each country, the tax rate schedule is translated in terms of the average earnings of production workers. Only central government taxes are taken into account; regional and local taxes, as well as social security contributions, are omitted.

\section{Social Protection}

The comparative data on and descriptions of social security systems in Germany, Sweden, and the United States are from the German Federal Ministry of Labour and Social Affairs, Social Security at a Glance, 2001, and the U.S. Social Security Administration, Office of Research, Evaluation and Statistics, Social Security Programs in the United States, 2000 , and from comparative charts published by both the U.S. Social Security Administration (Social Security Programs Throughout the World, 1999) and the Mutual Information System on Social Protection, an EU agency that gathers information on the social security systems of member countries (Social Security and Social Integration: Comparative Tables on Social Protection in the Member States, 2000). We report data on family benefits, health care, sickness benefits, unemployment benefits, disability benefits, and social assistance. Information on old-age and survivors' pensions was also available but disregarded for purposes of this paper.

\section{Minimum Wages}

The second and third columns of table 5 report measures of minimum wages for OECD countries that have national or statutory minimum wages; data are from Eurostat, Minimum Wages in the European Union, 2001; OECD Economic Outlook, no. 66, 1999; and OECD Main Economic Indicators (April 2001). The first column, reported from Nickell and Layard (1999), adds minimum wages for Germany and Sweden, which have sectoral minimum wages but no overall minimum wage policy. 


\section{Labor Market Regulation}

The labor market measures reported in table 6 are all from publications by Nickell (1997) and by Nickell and Layard (1999) and are constructed as follows.

The labor standards index is produced by the OECD (OECD Employment Outlook, 1994) and extended by Nickell and Layard (1999) and refers to the strength of legislation with regard to five different aspects of the labor market: working hours, fixed-term contracts, employment protection, minimum wages, and employees' representation rights. Each country is scored from 0 (no legislation) to 2 (strict legislation) for each measure. The maximum possible score is thus 10 .

Employment protection is measured by an OECD index referring to the legal framework concerning hiring and firing (from OECD Jobs Study, 1994). The maximum value is 20 and indicates the strictest legal provisions. Minimum annual leave is taken from the same OECD source and includes public holidays.

The benefit replacement ratio is the share of income replaced by unemployment benefits. Data are from the U.S. Social Security Administration, Social Security Programs Throughout the World, 1999. Benefit duration data are from the same source.

\section{Economic Volatility}

The first four measures reported in table 7 are from the OECD Statistical Compendium, 1960-1999, whereas data on terms-of-trade shocks are reported from Rodrik's (1998) database.

\section{Racial Fractionalization Measures}

We used the most recent demographic measures whenever they were available from national census bureaus (this was the case for Australia, Canada, France, India, Israel, New Zealand, Singapore, and the United States; most of these data are available online). However, for most countries we used the handbook by David Levinson (1998) and Minority Rights Group International, World Directory of Minorities, 1997, both of which 
provide detailed profiles of each country, including reports about the racial, ethnic, linguistic, and religious composition of the population. The index is computed as the probability of randomly drawing out of the country's population two individuals that do not belong to the same racial group.

\section{General Social Survey}

The General Social Survey (GSS) is conducted by the National Opinion Research Center in Chicago (Davis and Smith, 1999). The key dependent variable taken from the GSS is a scale (normalized to range between 0 and 1) indicating to what extent the respondent supports increased spending on welfare. The question is asked as follows: "We are faced with many problems in this country, none of which can be solved easily or inexpensively. I'm going to name some of these problems and for each one I'd like you to tell whether you think we're spending too much money on it, too little money, or about the right amount." Poverty is then one of the problems named.

Some of the key right-hand side variables in our analysis are also taken from the GSS, including the percentage of blacks in the respondent's own state, the belief that black people are lazy, and whether or not the respondent has had a black person over for dinner in the last five years. On the laziness question, respondents are asked to report their beliefs about people of various races and ethnicities. The question asks, "Do people in this group tend to be hardworking or lazy?" and people respond on a scale from 1 to 7 , with 7 being the laziest.

To study mobility we use a GSS variable that compares the respondent's own occupational prestige with that of his or her parents.

\section{World Values Survey}

The World Values Survey is produced by the Institute for Social Research at the University of Michigan (Inglehart and others, 2000). We use World Values Survey data to measure how individuals' attitudes toward social spending vary and how such attitudes correlate with beliefs about social mobility and about the laziness of the poor, and with the 
respondent's own characteristics. We use data from Belgium, Denmark, Finland, France, Germany, Ireland, Italy, the Netherlands, Norway, Spain, Sweden, Switzerland, the United Kingdom, and the United States.

Our dependent variable is a zero-one dummy for whether the respondent classifies himself or herself as being on the left side of the political spectrum. The survey uses a scale from 1 to 10 , and we identify as a leftist anyone who reports a 4 or lower. (The exact question is: "In political matters, people talk of 'the left' and 'the right.' How would you place your views on this scale, generally speaking?")

We use this question rather than more direct questions on social spending because all of the latter relate to the appropriateness of the current level of spending in one's own country. There are large differences across countries in the level of spending, and that level appears to affect how people respond to the question.

Our other variables of interest in the World Values Survey are responses to the following questions:

Why, in your opinion, are there people in this country who live in need? Here are two opinions: Which comes closest to your view?

They are poor because society treats them unfairly.

They are poor because of laziness and lack of will power.

In your opinion, do most poor people in this country have a chance of escaping from poverty, or is there very little chance of escaping?

They have a chance.

There is very little chance.

Respondents who choose the first of the two answers are assigned a score of zero, and those who choose the second are assigned a score of one. The final question asks the respondent to indicate agreement or disagreement with the following statements:

In the long run, hard work usually brings a better life.

Hard work doesn't generally bring success-it's more a matter of luck and connections.

Responses are coded on a scale of 1 to 10 , with 10 indicating a strong belief in luck. We rescaled this to range between 0 and 1 . 